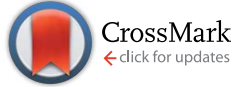

Cite this: RSC Adv., 2017, 7, 15027

Received 22nd December 2016 Accepted 28th February 2017

DOI: $10.1039 / c 6 r a 28581 c$

rsc.li/rsc-advances

\section{PDMS/camphor soot composite coating: towards a self-healing and a self-cleaning superhydrophobic surface $\dagger$}

\begin{abstract}
Bichitra N. Sahoo, ${ }^{a}$ Sonil Nanda, ${ }^{b}$ Janusz A. Kozinskib and Sushanta K. Mitra*a
A novel self-cleaning polymer composite with self-healing ability to self-repair after chemical and mechanical damage using readily available materials like polydimethylsiloxane (PDMS) and camphor soot particles is developed. With the optimal loading of the camphor soot particles, the composite coating on glass and stainless steel surfaces reveals self-cleaning properties with a water contact angle of $171^{\circ}$. We also demonstrate that any degradation of its surface energy under oxygen plasma etching can be recuperated, demonstrating the self-healing ability of the superhydrophobic surface. The fabricated PDMS/camphor soot hybrid coating exhibited excellent retention of superhydrophobicity against the impact of sand particles from a height of $10-70 \mathrm{~cm}$. In addition, after being damaged chemically by strong acid treatment ( $1 \mathrm{M} \mathrm{HNO}_{3}$ solution), the coating can also restore its properties after a short thermal cycle. The quantitative measurement of mechanical properties of self-healing superhydrophobic surfaces is challenging due to their high surface roughness at the micro/nano-scale with a tolerance of low stress. In this work, we have conducted a detailed investigation of the mechanical responses of the camphor soot particle-incorporated PDMS composites by using atomic force microscopy (AFM). Using an AFM tip with a radius of approximately $10 \mathrm{~nm}$, we have quantified different mechanical properties such as stiffness, the plastic work, and the effective adhesive work. Such versatile superhydrophobic surfaces can have wide applications ranging from underwater marine vessels to coating surfaces to protect them from moisture and unwanted penetration of water. These composite coatings are environmentally benign and can be readily coated on various substrates by simple spraying.
\end{abstract}

\section{Introduction}

During the past decade, artificially-made superhydrophobic polymeric surfaces that shield against dust and water-borne contaminants have been extensively studied for numerous potential applications including anti-corrosion, anti-fouling, self-cleaning, anti-icing and drag reduction. ${ }^{1-5}$ However, their robustness and energy efficiency in an outdoor environment is often questionable, thus, limiting their numerous practical applications. In addition, fabricating surfaces that can maintain low surface energy (phobic characteristics) during in situ applications to attain long lasting superhydrophobicity is still a challenge. It has been reported that often this low surface energy gets altered by external factors such as strong acid attack, sun bleaching, mechanical damage such as rubbing, scratches etc. Hence, the design and fabrication of nanostructured self-healing

${ }^{a}$ Micro \& Nano-scale Transport Laboratory, Lassonde School of Engineering, York University, Toronto, Ontario, M3J1P3, Canada.E-mail: mitras@yorku.ca

${ }^{b}$ Department of Earth and Space Science and Engineering, Lassonde School of Engineering, York University, Toronto, Ontario, M3J1P3, Canada

$\dagger$ Electronic supplementary information (ESI) available. See DOI: 10.1039/c6ra28581c (i.e., maintaining the low surface energy irrespective of external factors) polymeric materials with increased sustainability, excellent energy efficiency and well-defined robustness have been attracting significant interest within the scientific community in the last few decades. ${ }^{6}$ The healing of polymeric materials is based on the fact that the damaged exposed surface will retain its native hydrophobicity by adjusting its surface energy, thereby leading to restoration of superhydrophobicity. Thus, self-healing polymeric materials have gained explicit interest in recent years because these materials offer enormous opportunities where long-term mechanical durability in poorly accessible areas is important. ${ }^{7}$

Many approaches of healing strategies have existed for autonomic restoration of microscopic/nanoscale defects and cracks but materials that suffer large-scale damage have not been realized. To solve this problem, mechanically-durable superhydrophobic materials and physical re-mending methods have been developed, but autonomous recovery of superhydrophobicity is more desirable. Among the various self-healing materials, the polymeric composite films have been the leading materials due to their chemical and mechanical durability. ${ }^{\mathbf{8 9}}$ For the development of robust self-healing surfaces, Puretskiy et al. fabricated a selfhealing hydrophobic surface based on the combination of fluorinated crystalline fusible wax and colloidal particles. ${ }^{\mathbf{1 0 , 1 1}}$ The matrix, 
perfluorinated wax, was mixed with hydrophilic silane-modified silica nanoparticles with the formation of a hierarchical surface which demonstrated superhydrophobicity with water contact angle of $152^{\circ}$. Although the nanoparticles were removed from the topmost layer by mechanical damage, melting of the wax resulted in reshuffling of the surface micro/nanoparticles and their movement to the surface and restoration of the hydrophobicity. Another approach to improve the durability of a superhydrophobic surface is to use materials with the ability to regenerate the surface topography and/or reinstate the hydrophobicity. For example, Sun and co-workers demonstrated a self-healing porous coating which can be self-healed through the migration of low surface energy fluoroalkylsilane to the outermost layer. ${ }^{12}$ Similarly, by taking advantage of Layer by Layer assembly, they prepared a self-healing superhydrophobic porous polymeric coating, with a water contact angle of $158^{\circ}$. It possessed micro- and nano-scaled hierarchical structures of polyelectrolyte complexes of poly(allylamine hydrochloride) and sulfonated poly(ether ether ketone) with poly(acrylic acid). ${ }^{\mathbf{1 3 , 1 4}}$ The emphasis on restoring mechanical and structural properties of multiple healing areas of self-healing materials is still in its infancy despite their importance as an efficient protective layer.

To date, polydimethylsiloxane (PDMS) is one of the most used surface modifiers to generate self-healing surfaces. Introduction of hydrophobic modifier and binding agents of different types of materials such as polytetrafluoroethylene (PTFE) particles, tetraethyl orthosilicate (TEOS), candle soot, zinc oxide (ZnO), fumes silica and titania nano-particles, oligomeric silsesquioxane (POSS) nano-particles, graphene oxide, graphene, etc. are often used for the fabrication of superhydrophobic self-healing coatings. ${ }^{15-21}$ Many of these materials exhibit excellent results in terms of superhydrophobicity and robustness. Unfortunately, the majority of the reported superhydrophobic surfaces with multifunctional properties are not fabricated cost-effectively. Thus, it remains a big task to develop a novel cost-effective and self-healing superhydrophobic surface with durable mechanical properties, easy to apply over numerous substrates and ability to sustain in complex external environmental conditions.

Camphor soot particles which demonstrate high thermal conductivity and large specific surface area and good compatibility with polymeric materials have been used as efficient fillers in the fabrication of superhydrophobic composites. These properties prompt us to believe that incorporating camphor soot particles with appropriate polymeric materials might reveal selfhealing properties with adequate mechanical strength and chemical resistance upon strong acid attack. To the best of our knowledge, no such study has been reported so far. The advantage of using camphor soot particles instead of other nano-fillers is that only a small amount of camphor soot is required to achieve a dramatic enhancement in the water repellency behavior due to its multiple low surface energy functional groups. ${ }^{22}$

To address the aforementioned challenges, we demonstrate a novel self-healing superhydrophobic material fabricated with camphor soot particles and PDMS which: (1) can restore its selfcleaning characteristics upon damage, (2) can recover the materials' functionality, and (3) can be applied on numerous substrates using simple, low cost and scalable techniques. In this work, the coating materials were tested for durable mechanical robustness by sand impact test. Generally, surface treatment of polymer composites influences their physical and chemical properties which may have some impact on the prospective applications in pressure sensors, micro-optics, biomedical devices, micro/nanofabrications, etc. ${ }^{23}$ Thus, in this study we have investigated the chemical barrier properties of PDMS/camphor soot composites with exposure to $1 \mathrm{M}$ concentrated nitric acid $\left(\mathrm{HNO}_{3}\right)$ solution. The self-cleaning characteristics of a damaged surface from $\mathrm{HNO}_{3}$ solution treatment could be automatically reinstated in heat curing and tetrahydrofuran (THF) treatment. The healing performance of the PDMS/camphor soot particles composite surfaces were evaluated with the healing efficiency in terms of healing time and water repellency. The term "self-healing" here refers to the recuperation of superhydrophobicity of the coating. In our study, the polar groups appeared after oxygen plasma etching and chemical treatment of the surface that led in reduced hydrophobicity, heating the coating layer could increase the mobility of the PDMS/camphor soot polymer chains molecules. As a result of molecular rotation and movement, the introduced polar groups tended to be concealed inside the coating layer and more low surface energy chains became exposed to the surface, thereby healing the superhydrophobicity. In addition, $\mathrm{O}_{2}$ plasma etching adversely impacts the surface roughness and surface energy of the superhydrophobic PDMS/camphor soot particles. However, it could be automatically healed upon thermal cycle, indicating that the obtained superhydrophobic surfaces demonstrate excellent self-healing ability in both surface energy and surface roughness. Since the functionalities of these coatings are connected to the presence of micro/nano hierarchical structure and surface chemistry at the surfaces in the healing process, the replenishment of the low surface energy at the surface after impairment, as described later, is required to recuperate the coatings successfully. In addition, we have also focused on the evaluation of mechanical properties of self-healing superhydrophobic camphor soot particle induced PDMS coatings via atomic force microscopy (AFM) force measurements.

\section{Experimental section}

\subsection{Materials}

Camphor (96\%), ethanol (reagent grade), acetone (HPLC phase > 99.9\%), tetrahydrofuran (THF, anhydrous, 99.9\%), nitric acid (70\% concentration), diglycidyl ether of bisphenol A (DGEBA) and polyimide resin were purchased from Sigma-Aldrich, USA and used without further purification. A camphor tablet of $5 \times 5$ $\times 2 \mathrm{~mm}$ size was used as the source materials for generation of carbon soot particles. Camphor tablets were fired by using a lighter, which generated necessary flames. A single camphor tablet $(7 \times 5 \mathrm{~mm})$ was placed in a silica crucible, and the entire assembly was kept inside a polycarbonate chamber. The camphor soot particles were collected on a glass substrate placed $50 \mathrm{~mm}$ above the flame for 10 to $15 \mathrm{~s}$. The step-wise procedure for the collection of soot particles is schematically shown in Fig. 1. During the stipulated time period, the emitted soot particles were collected in a layered pattern over the glass substrate. The collected camphor soot particles were stored in glass bottles at 


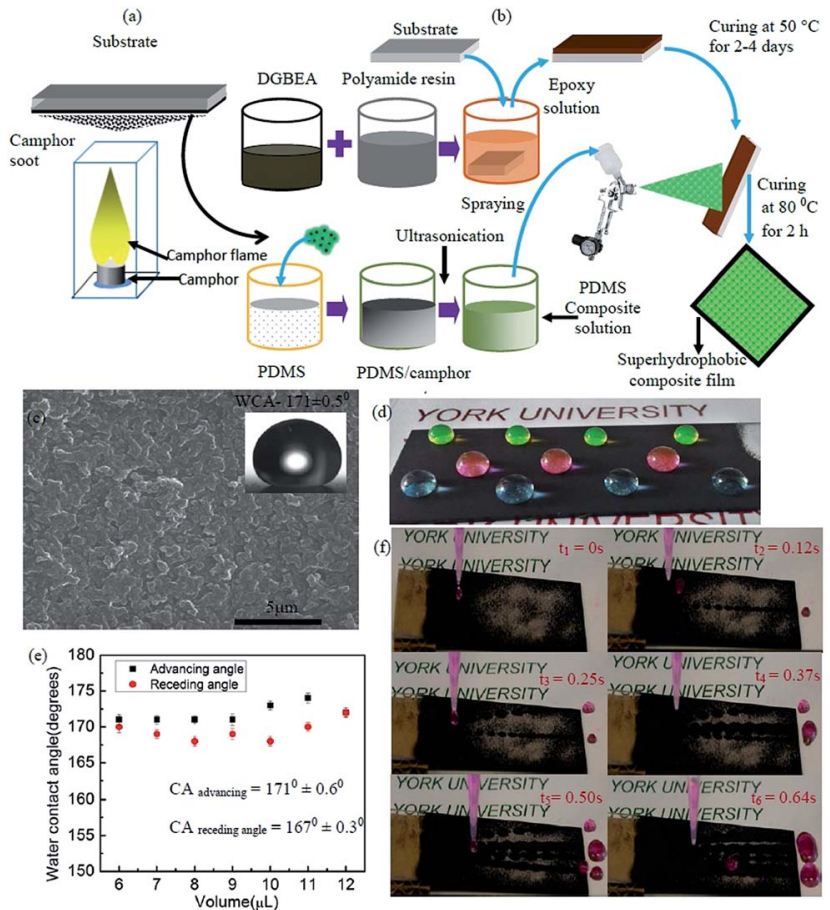

Fig. 1 (a) Scheme for collection of candle soot on the substrate. (b) Scheme for sample preparation: fabrication of superhydrophobic selfhealing PDMS/camphor soot composite films. (c) FESEM image of PDMS/camphor soot composite film. (d) Photographs of coloured liquid droplets on the PDMS/camphor soot composite films. (e) Advancing and receding angle measurements for water. (f) Snapshots for self-cleaning effect of PDMS/camphor soot composite films (with $\mathrm{TA}$ of $5^{\circ}$ ).

room temperature and atmospheric pressure without any post treatment. In addition, sublimation did not occur during camphor combustion process. ${ }^{22}$ Polydimethylsiloxane (PDMS, Sylgard 184 Silicone Elastomer Kit with components of PDMS base and curing agent) was purchased from Dow Corning Ltd. Commercial stainless steels plate $(30 \times 20 \times 1 \mathrm{~mm})$ and microscopic glass slide (Fisher Scientific, $75 \times 25 \times 2 \mathrm{~mm}$ ) were used as the substrate materials for the coating process. Deionized water used for measurement of the water contact angle experiments was generated by a Millipore water system. For the fabrication of coating on substrates, a spray gun $1.5 \mathrm{~mm}$ diameter nozzle size with operating pressure $>40$ psi and working pressure $>10 \mathrm{psi}$ ) was purchased from the local market.

\subsection{Preparation of PDMS/camphor soot composite solution}

Preparation of PDMS/camphor soot composite solution is comprised of three steps. In the first step, $0.1 \mathrm{~g}$ of PDMS was mixed in $30 \mathrm{~mL}$ of THF using a magnetic stirrer for $45 \mathrm{~min}$ at ambient temperature to form Solution-1. Similarly, $0.01 \mathrm{~g}$ of the corresponding curing agent was dissolved in $30 \mathrm{~mL}$ of THF to form Solution-2. In the second step, both Solutions- 1 and 2 were mixed together to form a PDMS/THF Solution-3 (1\%,w/w). In the third step, camphor soot particles (PDMS/camphor soot particles, $1: 1$ mass ratio) was dispersed in the prepared PDMS/ THF Solution-3 and subjected for ultrasonication for $10 \mathrm{~min}$ to form a coating solution. Similarly, a base-coat solution of epoxy resin was prepared by dissolving $0.3 \mathrm{~g}$ of DGEBA and $0.2 \mathrm{~g}$ of polyimide resin in $20 \mathrm{~mL}$ of $\mathrm{THF}$ with the aid of a magnetic stirrer.

\subsection{Fabrication of superhydrophobic surfaces}

Prior to the coating process, the glass substrates and stainless steel substrate with required dimensions were ultra-sonicated (Sonicator, Model EI-6LH-SP, Sl no. 1209-122) at $20 \mathrm{kHz}$ and $20 \mathrm{~W}$ in $20 \mathrm{~mL}$ ethanol/water for $30 \mathrm{~min}$ followed by deionised water for $5 \mathrm{~min}$. The cleaned glass substrates were used as the base material as well as for the collection of soot particles. The preparation of superhydrophobic PDMS/camphor soot composite comprised of three steps. In the first step, the substrates were immersed into the prepared epoxy coating solutions for $30 \mathrm{~min}$ and cured at $50{ }^{\circ} \mathrm{C}$ for $48 \mathrm{~h}$ to obtain a primary coating. In the next step, these epoxy coated samples were spraycoated with PDMS/camphor soot composite solution. During the spraying process, the gap between the substrates and nozzle of the spray gun maintained was $100-150 \mathrm{~mm}$. The duration of spraying was $30 \mathrm{~s}$, and the process was carried out five times for each sample to obtain a thin homogeneous coating. Finally, the PDMS/camphor soot coated substrates were cured at $80^{\circ} \mathrm{C}$ for $3 \mathrm{~h}$ to obtain the stable superhydrophobic surface. The thickness of the final coating was 50-60 $\mu \mathrm{m}$.

\subsection{Measurement of static and dynamic water contact angle}

Sessile drop water contact angles (WCA) and dynamic water contact angle were measured using a custom-made contact angle measurement instrument located in Micro \& Nano-scale Transport Laboratory, Lassonde School of Engineering. The static contact angle was recorded by dropping a water droplet having a volume of $6 \mu \mathrm{L}$ on the surface and recorded after $30 \mathrm{~s}$ of droplet stability. The advancing and receding contact angles were measured by increasing and decreasing of a water droplet of $6 \mu \mathrm{L}$, respectively. Each WCA was an average of five different locations on the samples. The sliding angles were obtained four times for each sample by tilting the sample with a droplet on it until the droplet began to slide.

\subsection{Robustness test of PDMS/camphor soot composite films}

To investigate the mechanical resistance of the coating, sand abrasion test was performed. The PDMS/camphor soot composite surface was abraded by sand grains with average particle diameter of $200 \mu \mathrm{m}$ from a height of 10 to $70 \mathrm{~cm}$ at $45^{\circ}$ angle. The impact time for each sand abrasion test was approximately $120 \mathrm{~s}$. For each sand impact test, the drainage rate of the sand grains was controlled at approximately $1 \mathrm{~g} \mathrm{~s}^{-1}$. Furthermore, the thickness of the coating was also measured after each abrasion test.

\subsection{Healing test of PDMS/camphor soot composite film}

The composite films were subjected to $\mathrm{O}_{2}$ plasma treatment to destroy the surface chemistry. The $\mathrm{O}_{2}$ plasma treating was conducted with a plasma cleaner (Haric Plasma, PDC-001-HP 
(115 V); PDC-002-HP (230 V)) at $110 \mathrm{~Pa}$ and $30 \mathrm{~W}$ for about $30 \mathrm{~s}$. The treated samples were then heated at $125{ }^{\circ} \mathrm{C}$ for $30 \mathrm{~min}$ to reorganize the surface morphology and replenishing low surface energy functional groups. Similarly, acid barrier test of PDMS/ camphor composite films was carried out for investigating the healing ability of composite films. To investigate the acid barrier test, PDMS/camphor soot composite solution coated glass substrates were immersed into the prepared $1 \mathrm{M} \mathrm{HNO}_{3}$ solution for $48 \mathrm{~h}$. For healing by heat treatment, the samples were then heated at $50{ }^{\circ} \mathrm{C}$ for $35 \mathrm{~min}$. For healing by THF treatment, the $\mathrm{HNO}_{3}$ solution treated coatings were immersed into THF solution for over $5-10 \mathrm{~s}$ and then cured at $50{ }^{\circ} \mathrm{C}$ for 5 min. Both healed samples $\left(\mathrm{O}_{2}\right.$ plasma treated and $\mathrm{HNO}_{3}$ solution treated) were kept at room temperature, and the WCA was measured.

\subsection{Self-cleaning test}

Spray-coated glass substrates of all three types of healing samples (sand abrasion test, $\mathrm{O}_{2}$ plasma etching and $\mathrm{HNO}_{3}$ acid etching) were placed with required tilting angle. Sand grains with a mesh size of $200 \mu \mathrm{m}$ were spread over the spray coated samples. A high definition video camera (Nikon D5200) was used to record the self-cleaning action via rolling droplets of water on the surface.

\subsection{Material characterization}

The morphology of PDMS/camphor soot particles composite films were characterized by SEM (Scanning Electron Microscopy, Quanta 3D FEG, FEI, Hillsboro, Oregon, USA). Furthermore, high-resolution Transmission Electron Microscopy was (HR-TEM (FEI Tecnai TF20 operated at $200 \mathrm{kV}$ )) performed to analyse the morphology of camphor soot particles. XPS measurements of were carried out on a Thermo Scientific KAlpha XPS spectrophotometer (E.grinstead, UK) to detect the presence of surface elements. Thermo Advantage software (version 5.926) was used to perform curve fitting and to calculate the atomic concentrations. Raman microscopy imaging for the polymer composites samples was performed using a Renishaw inVia Reflex Raman microscope (Renishaw Inc., Illinois, USA) equipped with $514.5 \mathrm{~nm}$ Ar laser (Modulaser Model, Centerville, UT, USA), a 1800 line per mm grating and a CCD (charge-couple device) detector which provides a spectral resolution of approximately $1 \mathrm{~cm}^{-1}$. The laser was focussed onto the sample using $20 \times$ NPLAN objective $(\mathrm{NA}=0.40)$, and the laser power was measured at $3.5 \mathrm{~mW}$ at the sample. Raman imaging maps were collected in Streamline ${ }^{\mathrm{TM}}$ mode using a range of $1100-1700 \mathrm{~cm}^{-1}$ and a $60 \mathrm{~s}$ of acquisition time. The pixel size for the maps was $3 \mu \mathrm{m} \times 3 \mu \mathrm{m}$. The resulting Raman spectra from maps were deconvoluted with a 5 peak fit using the WiRE $^{\mathrm{TM}}$ software (V3.4). ${ }^{24}$ The Raman images were processed using Gwyddion imaging process software (V2.45). The instrument's calibration was verified using a $\mathrm{Si}(110)$ reference sample, which was measured at $520 \mathrm{~cm}^{-1}$. Atomic force microscopy (AFM) analysis was performed using an Agilent 4500 AFM microscope (Agilent Technologies Ltd., Tempe, AZ, USA) operating in intermittent contact mode. A silicon cantilever (NSG-L,
K-Tek Nanotechnology LLC, Wilsonville, OR, USA) with specifications of a force constant of $58 \mathrm{~N} \mathrm{~m}^{-1}$, resonant frequency of $190 \mathrm{kHz}$, and a tip curvature radius of less than $10 \mathrm{~nm}$ was used for topography imaging. The imaging was done at a scan rate of 0.3-0.5 line per s (512 pixels per line) and a set-point oscillation amplitude to free air oscillation of $0.75-0.85$ with resonant amplitude of 5-6 V. Scanning Probe Image Processor (version 5.1.6) (Image Metrology, Horsholm, Denmark) was used for image processing. Similarly, nanoscale mechanical testing was performed with a Si cantilever (Vistaprobes, Nanoscience Instruments, Tempe, AZ) with a manufacturer's specification of a force constant of $3 \mathrm{~N} \mathrm{~m}^{-1}$, and a radius of curvature less than $10 \mathrm{~nm}$. The deflection sensitivity was calibrated using a fresh piece of mica. All force-displacement curves were performed under ambient conditions, and curves were collected from 4-5 different locations on the samples. To perform characterization of the mechanical properties, we have considered four parameters such as stiffness $(\delta)$, maximum indentation force $\left(F_{\max }\right)$, plastic work ( $\left.W_{\text {plastic }}\right)$ and effective adhesion work ( $\left.W_{\text {adhesive }}\right)$. The slope of the retraction curve provides the stiffness of the surface. Similarly, the effective plastic work and the effective adhesive work are given by the integrals of force over displacement on approach and retract, respectively.

\section{Results and discussion}

The surface structure of the PDMS/camphor soot composite coating developed via the solution immersion and spraying technique is shown in Fig. 1a and b. As shown in Fig. 1a, a glass slide is held above the flame of a camphor tablet for the collection of soot particles. The camphor soot particles are comprised of carbon nano-particles with the diameter of 40$100 \mathrm{~nm}$ that are loosely connected by van der Waal forces (Fig. S1a $\dagger$ ). ${ }^{25}$ Fig. 1b illustrates the detailed strategy for fabrication of our superhydrophobic self-healing coatings. A mechanically durable robust superhydrophobic PDMS/ camphor soot composite surfaces were generated using simple spraying technique followed by solution immersion process. Fig. 1c shows the FESEM image of the PDMS/camphor soot coatings after curing at $80^{\circ} \mathrm{C}$ for $3 \mathrm{~h}$. It can be seen that the surface is uniformly and densely covered with micro/nanofeatures with sufficient roughness to demonstrate the selfcleaning effect. In addition to SEM, the roughness of the superhydrophobic glass surface was examined by AFM of plain PDMS/camphor soot composite film. As shown in Fig. S1b, $\uparrow$ the surface structure illustrates micro-scale roughness superimposed with nanostructures, which reveals a high root-meansquare (rms) roughness of $1491 \mathrm{~nm}$. The inset image in Fig. 1c demonstrates the shape of a water droplet (water contact angle of $171 \pm 0.5^{\circ}$ ) on superhydrophobic PDMS/camphor soot composite surfaces. It is remarkable to notice many protrusions that uniformly cover the surface and trap the air in between them, which is essential for enhancing superhydrophobicity. ${ }^{26}$ This superhydrophobicity is reflected by the high contact angle for a wide variety of fluorescent colored water droplets (Fig. 1d). The advancing angle and receding angles of the PDMS/camphor soot composite surfaces were measured and shown in Fig. 1e. It 
is observed that a $6 \mu \mathrm{L}$ water droplet possess a contact angle of more than $165^{\circ}$ with contact angle hysteresis less than $6^{\circ}$. With respect to surface roughness and low surface energy of the PDMS composite layer, a very small contact angle hysteresis of $2-4^{\circ}$ is revealed. This is because most commonly used coatings developed by brushing, spraying and spin-coating techniques do not reveal self-cleaning properties. Thus, we demonstrate in Fig. 1f that the PDMS/camphor soot composite surface coated glass slides exhibited excellent water repellent properties. This is evident by the fact that $6 \mu \mathrm{L}$ of water droplets rolled off easily on tilted surface with a tilt angle of $5^{\circ}$ without leaving any sand grains behind on the PDMS composite surface, which illustrates self-cleaning property (Movie clip S1†). As shown in Fig. 1f, the time lapse snapshots were taken before and after flowing of water droplets on the coated surfaces to understand the selfcleaning effect of the surfaces. It is observed that an average time duration of $0.15 \mathrm{~s}$ is required for $6 \mu \mathrm{L}$ water droplets to roll off on PDMS/camphor soot coated surface.

\subsection{Sand abrasion test of PDMS/camphor soot composite surface}

To date, the poor mechanical stability of superhydrophobic surface is one of the greatest problems, which limits their wide use in industrial applications. In the real world applications, even a minor scratch or a small external force could destroy the surface topography and reduce the superhydrophobicity. In an effort to evaluate the mechanical durability and robustness of the prepared superhydrophobic PDMS/camphor soot composite films, sand impact test was carried out using a custommade sand impact tester. As shown in Fig. 2a, the spray-coated composite films were attached at an angle of $45^{\circ}$ and impacted with sands grains (average diameter $200 \mu \mathrm{m}$ ) from a height varying between $10 \mathrm{~cm}$ to $70 \mathrm{~cm}$. After sand impact test, the surfaces remained superhydrophobic, i.e., water droplets rolled off easily. The sand impact test was controlled at approximately $1 \mathrm{~g} \mathrm{~s}^{-1}$. The durability of our superhydrophobic PDMS/ camphor soot composite films against impacting can be computed by measuring the impact energy of sand grains as shown in eqn (1):

$$
E_{\text {impact }}=m g h=\rho \times \frac{4}{3} \pi r^{3} \times g \times h
$$

Here ' $\rho$ ' is the density of silica sand grains $\left(2 \mathrm{~g} \mathrm{~cm}^{-3}\right)$, ' $g$ ' is the acceleration due to gravity, ' $h$ ' is the height of impact and ' $r$ ' is the average radius of sand grains (i.e., $100 \mu \mathrm{m}$ ). The corresponding static contact angle of PDMS/camphor soot composites films were calculated after each impact test, as shown in Fig. 2b. After each impact test, the sliding angle was measured, which demonstrates that PDMS/camphor soot composite films have excellent water repellency tendencies (Fig. 2b). This demonstrates that original superhydrophobicity of the surface is restored after it is impacted by sand grains from a height of $10-70 \mathrm{~cm}$ corresponding to the impinging energy of $8.3 \times 10^{-9}$ to $58.64 \times 10^{-9} \mathrm{~J} \mathrm{~g}^{-1}$ (Table $\left.\mathrm{S} 1 \dagger\right) .^{27}$

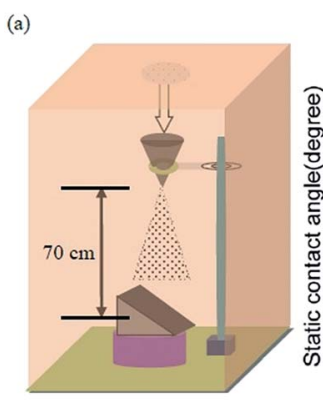

(b)
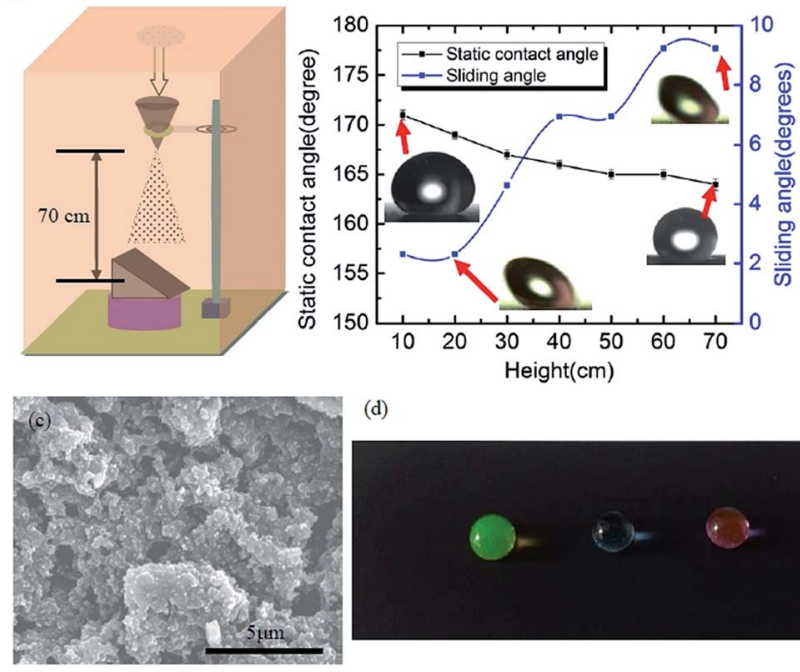

(d)

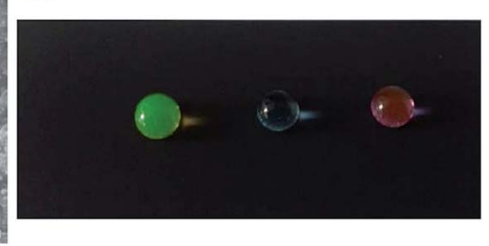

Fig. 2 (a) Schematic diagram for sand abrasion experiment. (b) Static contact angle and sliding angle changes with impact height of sand grains. (c) FESEM image of coated surface after sand abrasion from $70 \mathrm{~cm}$ height. (d) Photographs of coloured water droplets on PDMS composite surfaces.

To investigate the stability of our superhydrophobic PDMS/ camphor soot composite films toward outdoor applications, we quantified the corresponding impact velocity $\left(V_{\text {impact }}\right)$ of sand grains as:

$$
\begin{aligned}
E_{\text {impact }} & =\frac{1}{2} m v_{\text {impact }}^{2}=\rho \times \frac{4}{3} \pi r^{3} \times v_{\text {impact }}^{2}, \\
v_{\text {impact }} & =\sqrt{\frac{2 E_{\text {impact }}}{\frac{4}{3} \pi r^{3} \rho}}
\end{aligned}
$$

Considering the radius of sand grains $(r=100 \mu \mathrm{m})$ and their density $\left(2 \mathrm{~g} \mathrm{~cm}^{-3}\right)$, our superhydrophobic surfaces could withstand impact velocities up to $13.45 \mathrm{~km} \mathrm{~h}^{-1} \cdot{ }^{19,27}$ As shown in Fig. 2c, although the surfaces are roughened after being impacted several times, they still demonstrate superhydrophobicity with water contact angle up to $164^{\circ}$ and sliding angle less than $10^{\circ}$. Furthermore, Fig. 2d clearly illustrates the shape of water droplets which reflect the superhydrophobicity of the composite surfaces. The slight decrease in the water contact angle and a little increase in the sliding angle reveal that a partial loss of surface energy and its texture during the sand impact process. The magnified image reveals collapsed micro/ nano structures after being sand blasted from a height of $70 \mathrm{~cm}$ (i.e., $E_{\text {impinged }}$ of $58.6 \times 10^{-9} \mathrm{~J}$ per grain with $I_{\text {velocity }}$ of $13.4 \mathrm{~km} \mathrm{~h}^{-1}$ ). Such collapse of the microstructure of the coating surfaces was comprised of a network of camphor soot particle covered with PDMS. Furthermore, mechanical durability of the coatings is not yet clearly understood because of the partial loss or breakage of the texture of the surface during sand impact test. Thus, we have measured the water contact angle and thickness of the coatings after each abrasion test. It is seen that the thickness of the coatings is maintained between $50-60 \mu \mathrm{m}$ 
despite partial damage of texture. As thicker coatings illustrate more damage resistance against sand impact, hence partial damage of texture does not affect the thickness and wettability of the coatings. To further study the adhesion of the coatings, we have immersed the samples into an ethanol solution for $2 \mathrm{~h}$, which was later ultra-sonicated for $30 \mathrm{~min}$. The surfaces still keep water contact angle $>165^{\circ}$ and a sliding angle of $4^{\circ}$, after the ultra-sonication process. Further, this result significantly confirms excellent adhesion and robustness of the coatings. Therefore, the mechanical durability of PDMS/camphor soot composite surfaces can significantly increase the lifespan and enhance the reliability amid harsh conditions in outdoor applications. The mechanical durability of the obtained PDMS composite coating was investigated using sand grains impact and ethanol immersion test. The sand grain impact experiment, as shown in Fig. 2, simulate the necessary outside harsh environment such as impact from rain drops, etc.

\subsection{Recovery of superhydrophobicity on PDMS/camphor soot composite surfaces}

The self-healing ability of spray coated superhydrophobic PDMS/camphor soot is examined by etching with $\mathrm{O}_{2}$ plasma. It is seen that the etched sample under plasma treatment for $30 \mathrm{~s}$ turned the superhydrophobic coatings into superhydrophilic ones. It was found that the surface was instantly wetted by a drop of water. This transformation to superhydrophilic is caused by the decomposition of the PDMS composite coatings and the incorporation of polar groups into the surfaces. ${ }^{28}$ The damaged surface of original superhydrophobic composite films reorganize its texture after being exposed to ambient temperature for 2-3 days. This indicates that the hydrophilic PDMS composite surface is again covered with hydrophobic PDMS/ camphor soot layer. During heat treatment, the induced low surface energy molecules were ejected and migrated on the surface and reorganized to lower the surface energy, thereby enhancing the hydrophobicity. ${ }^{29}$ Fig. $1 \mathrm{c}$ and $3 \mathrm{a}$ show the FESEM images of the PDMS/camphor soot composite surface before and after $\mathrm{O}_{2}$ plasma treatment. It is clearly seen that there is no noticeable variation of surface microstructure after $\mathrm{O}_{2}$ plasma treatment. However, the variation of surface chemistry of the surface upon $\mathrm{O}_{2}$ plasma etching would be the main aspect that brings the change of surface wettability. As demonstrated in Fig. 3a, after $\mathrm{O}_{2}$ plasma treatment for about $30 \mathrm{~s}$, the superhydrophobic PDMS/camphor soot composite films become superhydrophilic and recuperate its superhydrophobicity after heating to $125{ }^{\circ} \mathrm{C}$ for about $30 \mathrm{~min}$. Thus, confirmation of the self-healing ability of the coatings was examined by consecutively exposing the superhydrophobic PDMS/camphor soot composite films to $\mathrm{O}_{2}$ plasma treatment and heating cycles. From Fig. 3b, it is clearly seen that after 12 cycles of etchinghealing practice, the surface regains its superhydrophobicity, which suggests that the prepared PDMS composite surface has an excellent self-healing ability. Furthermore, the increase in the number of cycles does not require more time than $30 \mathrm{~min}$ to regain the superhydrophobicity of the surfaces, indicating that healing of the surface is consistently maintained for each cycle.
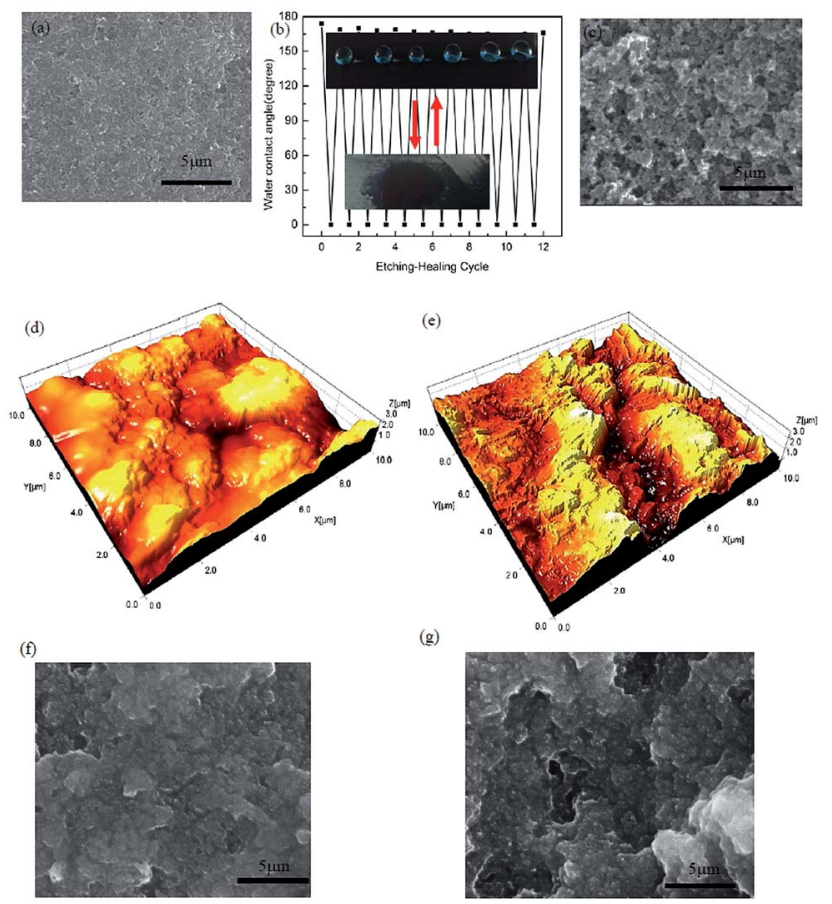

(g)

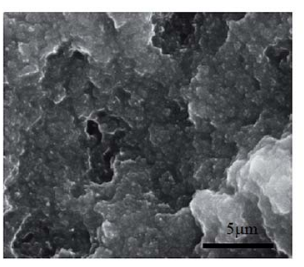

Fig. 3 (a) FESEM images of PDMS composite surface after $\mathrm{O}_{2}$ plasma treating, (b) water contact-angle changes of the PDMS/camphor soot coated surface upon repeated $\mathrm{O}_{2}$ plasma etching and self-healing. Inset: shapes of water droplets $(6 \mu \mathrm{L})$ of the as prepared and healed (top), $\mathrm{O}_{2}$-plasma-etched (bottom). (c) FESEM image of plasma treated PDMS/camphor soot coated surface after 12 cycles. (d) 3D AFM image of plasma etched PDMS/camphor soot composite surface. (e) 3D AFM image of plasma etched PDMS/camphor soot composite surface healed by heating. FESEM images of $\mathrm{O}_{2}$ plasma etched PDMS composite surface after heated for (f) $24 \mathrm{~h}$ and (g) $48 \mathrm{~h}$.

The rearrangement of the PDMS polymer chain may be restricted due to the introduction of camphor soot particles in the PDMS composites, which minimizes the degradation of PDMS chains. Thus, during $\mathrm{O}_{2}$ plasma treatment the introduced $-\mathrm{OH}$ groups do not get disturbed by each healing cycle. To best of our knowledge, there is a very limited report about such composite surfaces up to till now, which describes selfhealing performance of coatings without degradation of PDMS chains. Fig. S2 $\uparrow$ illustrates the variation of water contact angle of the $\mathrm{O}_{2}$ plasma etched PDMS/camphor soot composite films correspond to the healing time at $125{ }^{\circ} \mathrm{C}$. It is clearly observed that the water contact angle rises as the heating time is increased, and it restores its superhydrophobicity after $30 \mathrm{~min}$. Furthermore, it is also observed that after each etching-heating cycle, the sliding angle of the surface is enhanced significantly. Thus, water droplet remains sticking to the surface even with the surface being turned upside down. ${ }^{31,32}$ To verify this, the self-cleaning effect (Movie clip S2 $\dagger$ ) of the coating is examined, as shown in Fig. S3. $\dagger$ A water droplet having volume of $6 \mu \mathrm{L}$ was deposited on the coating surface followed by tilting the surface until the water starts to roll off. It is clearly observed that $6 \mu \mathrm{L}$ of water droplet takes an average of $0.15 \mathrm{~s}$ to roll off on the surface. Fig. 3c shows the FESEM image of a healed surface, which is treated by $\mathrm{O}_{2}$ plasma followed by heating. The surface 
morphology and roughness of the oxygen plasma treated PDMS/ camphor soot composite coated glass slides and same surface healed upon heating were further examined by AFM.

As illustrated in Fig. 3d, the 3D AFM images of the $\mathrm{O}_{2}$ plasma treated PDMS/camphor soot composite surface reveals rms roughness of $1303 \mathrm{~nm}$. Upon oxygen plasma treatment of PDMS/camphor soot, the surface roughness decreases from 1491 to $1303 \mathrm{~nm}$. It indicates that upon $\mathrm{O}_{2}$ plasma treatment, the surface microstructure becomes smooth. However, after heating at $125{ }^{\circ} \mathrm{C}$, for $30 \mathrm{~min}$, the surface microstructure recovers completely. One can observe that as the heating time is increased to $30 \mathrm{~min}$, both restoration of micro/nano surface structure and the surface WCA increase, further confirming the enhanced effect of surface microstructure on surface wettability (Fig. 3e). When the damaged PDMS/camphor soot composite surface was heated, sublimation of camphor did not occur. Fig. $3 \mathrm{f}$ and $\mathrm{g}$ show the FESEM images of the $\mathrm{O}_{2}$ plasma etched PDMS/camphor soot composite surface heated for 24 and $48 \mathrm{~h}$ respectively. As shown in both Figures, it is clearly visible that long time heating did not change in morphology of the coating. It was found that the initial superhydrophilic surface became superhydrophobic with water contact angle of $162 \pm 2^{\circ}$.

3.2.1 Self-healing and self-cleaning ability of $\mathrm{O}_{2}$ plasma etched PDMS/camphor soot particles composite surface. Superhydrophobic surface with self-cleaning property can be generated by the combination of surface topographies and low surface materials. The obtained self-healing property of PDMS/ camphor soot particles composite films can be attributed to the following reasons: (1) re-organization of surface micro/nano structures, and (2) migration of low surface energy functional groups to the outer surface during heating process of plasma etched samples. X-ray photoelectron spectroscopy (XPS) was used to analyze the surface elemental composition of PDMS composite coatings. It reveals the chemical composition and elemental composition on the surface of the coatings. As shown in Fig. 4a, XPS spectra of PDMS/camphor soot composite film and $\mathrm{O}_{2}$ plasma treated PDMS/camphor soot composite film for $30 \mathrm{~s}$ reveal some changes in the elemental composition. For example, the Si 2 p signal of PDMS composites did not change after the treatment while the $\mathrm{O} 1 \mathrm{~s}$ signal increased and $\mathrm{C} 1 \mathrm{~s}$ signal decreased after the plasma irradiation (Fig. S4a $\uparrow$ ). ${ }^{30}$ Upon plasma treatment, the generation of hydroxyl groups on PDMS composite films surface causes the changes in $\mathrm{C}$ 1s and $\mathrm{O} 1 \mathrm{~s}$ signals.

Curve fitting of C $1 \mathrm{~s}, \mathrm{O} 1 \mathrm{~s}$ and Si $2 \mathrm{p}_{3}$ XPS spectra of PDMS composite film, plasma treated PDMS composite surface and plasma treated PDMS composite surface healed by heating were performed by Gaussian-Lorentzian peak shape after performing background corrections (Fig. S5†). ${ }^{33,34}$ Effects of these macroscopic observations on wettability were supported by angle-resolved XPS in which the chemical composition of surfaces was demonstrated (Table S2 $\dagger$ ). Three major peaks of Si $2 \mathrm{p}_{3}, \mathrm{O} 1 \mathrm{~s}$, and $\mathrm{C} 1 \mathrm{~s}$ detected in the survey scan were investigated at high-resolution to examine the major components of PDMS composites, i.e., carbon, oxygen and silicon (Fig. S5a-i†). The percentage of area under Si $2 \mathrm{p}_{3}$ peak at $102.03 \mathrm{eV}$ for the surface of PDMS composite significantly decreased upon $\mathrm{O}_{2}$ plasma (a)

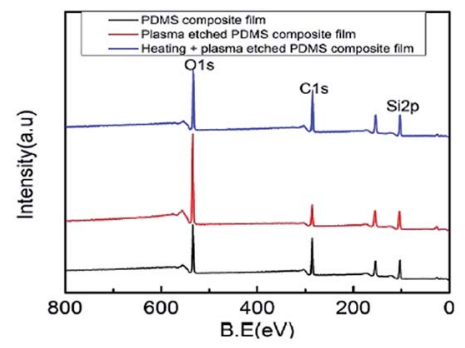

(b)

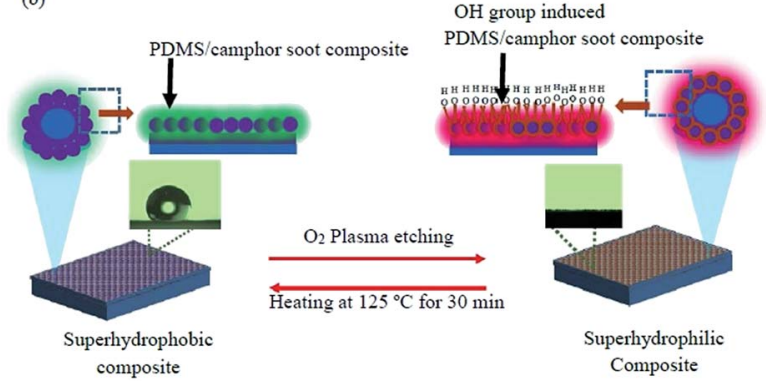

Fig. 4 (a) XPS spectra of PDMS composite surfaces, plasma treated PDMS composite surfaces and the same coating healed by heating at $125^{\circ} \mathrm{C}$ for $30 \mathrm{~min}$. (b) Schematic illustration of the self-healing process.

treatment from $83.03 \%$ to $40.08 \%$, while $\mathrm{Si} 2 \mathrm{p}_{3}$ peak at $103.51 \mathrm{eV}$ increases from $16.97 \%$ to $59.92 \%$ (Table S2†). Furthermore, content area for $\mathrm{Si}_{2} \mathrm{p}_{3}$ peak at $102.03 \mathrm{eV}$ at the surface of PDMS composite significantly increased upon heating of $\mathrm{O}_{2}$ plasma treated surface from $40.08 \%$ to $80.56 \%$, while Si $2 \mathrm{p}_{3}$ peak at $103.51 \mathrm{eV}$ decreases from $59.92 \%$ to $19.44 \%$. Similarly, content area for $\mathrm{O} 1 \mathrm{~s}$ peak $(92.55 \%)$ assigned to $532.41 \mathrm{eV}$ at the surface of PDMS composite decreased to $45.74 \%$ corresponding to $532.43 \mathrm{eV}$ upon $\mathrm{O}_{2}$ plasma treatment, while percentage of $\mathrm{O} 1 \mathrm{~s}$ peak at $533.55 \mathrm{eV}$ increases from $5.96 \%$ to $49.95 \%$ (Table $\mathrm{S} 2 \dagger$ ). The content area for O $1 \mathrm{~s}$ peak at $532.40 \mathrm{eV}$ at the surface of PDMS composite significantly increased from $45.74 \%$ to $91.98 \%$, while $\mathrm{O}$ 1s peak at $533.18 \mathrm{eV}$ decreases from $49.95 \%$ to $6.64 \%$ upon heating of $\mathrm{O}_{2}$ plasma treated surface at $125^{\circ} \mathrm{C}$ for $30 \mathrm{~s}$.

The repeating units $\left(-\mathrm{OSi}\left(\mathrm{CH}_{3}\right)_{2}{ }^{-}\right)$of PDMS illustrate the hydrophobicity of the composite films. However, this chemical structure leads to a hydrophilic state upon exposing this surface to $\mathrm{O}_{2}$ plasma that introduces silanol $(\mathrm{Si}-\mathrm{OH})$ groups and destroys methyl groups $\left(\mathrm{Si}-\mathrm{CH}_{3}\right)$, making the surface hydrophilic. $^{35,36}$ The main peak of $\mathrm{C} 1 \mathrm{~s}$ spectrum of PDMS composite surface (Fig. S5a $\dagger$ ), plasma treated PDMS composite surface (Fig. S5d $\dagger$ ) and same surface healed by heating (Fig. S5g $\dagger$ ) at 284.5 to $284.63 \mathrm{eV}$ are assigned to $\mathrm{C}-\mathrm{C}$ and $\mathrm{C}-\mathrm{H}$ bodings. In addition, another four peaks also existed with chemical shifts of $+1,+2,+3.5$ and $+3.9 \mathrm{eV}$ for each PDMS composite surfaces, which are typically assigned to $\mathrm{C}-\mathrm{O}$ (hydroxyl carbon), $\mathrm{C}-\mathrm{O}-\mathrm{C}$ (epoxy carbon), $\mathrm{C}=\mathrm{O}$ (carbonyl carbon) and $\mathrm{O}-\mathrm{C}=\mathrm{O}$ (carboxylate carbon) functional groups, respectively. It is clearly seen that upon plasma treatment of PDMS composite surface, the percentage of $\mathrm{O} 1 \mathrm{~s}$ peak at $284.63 \mathrm{eV}$ decreases from $93.38 \%$ to $87.39 \%$, while the percentage of other oxygen species increases significantly. ${ }^{37,38}$ The percentage of functional groups 
containing oxygen also reduces for PDMS/composite surface healed by heating (Table S2 $\dagger$ ).

The large full width at half maximum (FWHM) of $\mathrm{Si} 2 \mathrm{p}_{3}$ peaks at $102.03 \mathrm{eV}$ decreases from 1.23 to 1.15 significantly upon plasma treatment of PDMS composite surface and further increases for healed surface upon heating, while for Si $2 \mathrm{p}_{3}$, the peak at $103.51 \mathrm{eV}$ increases from 1.23 to 1.39 and significantly reduces upon heating. However, FWHM of C 1s peak increases from 1.09 to 1.20 significantly upon plasma treatment of PDMS composite surface and further decreases for healed surface upon heating. ${ }^{39}$ As illustrated in Fig. 4b, upon $\mathrm{O}_{2}$ plasma etching of PDMS composite surface for $30 \mathrm{~s}$, many polar groups are generated which cause superhydrophobicity. When the PDMS composite coating was damaged using plasma treatment, the hydroxyl groups $(-\mathrm{OH})$ are induced, thus exhibiting to superhydrophilicity and increasing the surface free energy. However, after exposure to $125{ }^{\circ} \mathrm{C}$ for $30 \mathrm{~min}$, the damaged surface restored its micro/nano structure and illustrated superhydrophobicity. As the glass transition temperature of PDMS is very low, the mobility of molecular migration as well as the rotation and movement of PDMS chains occurred. As it is a thermodynamically driven process, it reduces the surface energy of the chains. As a result, the introduced hydrophilic groups tend to be hidden inside the coating layer, and more PDMS structures were exposed to the surface, thus resulting in the restoration of micro/nano-structures. In contrast, $\mathrm{O}_{2}$ plasma treated surface recognizes its microstructure and covers with hydrophobic non-polar groups upon heating at $125{ }^{\circ} \mathrm{C}$ for $30 \mathrm{~min}$.

Raman spectroscopy is a beneficial tool in evaluating the structural features of carbonaceous materials as it is sensitive to both crystalline and amorphous polymorphs of carbon. As shown in Fig. S6† and 5, the plain PDMS/camphor soot composite film and $\mathrm{O}_{2}$ plasma etched composite film show the development of $\mathrm{D}$ and $\mathrm{G}$ bands at variable intensities. Raman spectra of plain PDMS/camphor soot composite film showed the significant increase in two broad bands at 1350-1365 and $\sim 1600 \mathrm{~cm}^{-1}$. The characteristic broad bands in the Raman spectra at 1350-1365 and 1537-1540 $\mathrm{cm}^{-1}$ represent the defect
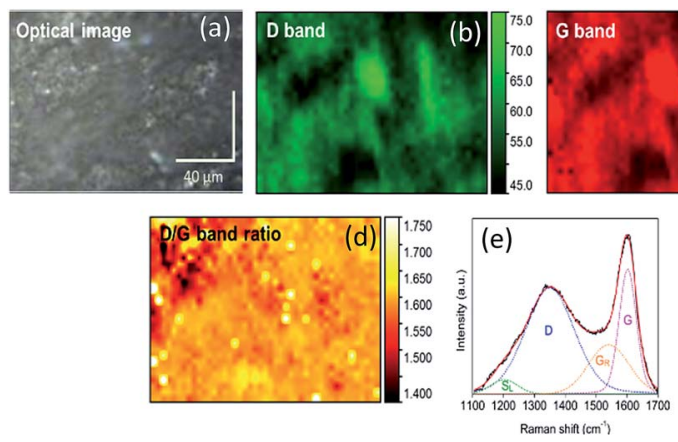

Fig. 5 Chemical maps generated through Raman spectroscopy of healed $\mathrm{O}_{2}$ plasma treated PDMS/camphor soot composite film upon heating. (a) Optical CCD image. (b) D band (mapping region: 1350$1365 \mathrm{~cm}^{-1}$ ). (c) $G$ band (mapping region: $1537-1540 \mathrm{~cm}^{-1}$ ) (d) $D / G$ band ratio. (e) Raman spectral acquisition at $514 \mathrm{~nm}$ (from 1100 to 1700 $\mathrm{cm}^{-1}$ ).
(D band) and graphite (G band) carbon structures, respectively. ${ }^{40}$

The Raman spectra in the range of $1100-1700 \mathrm{~cm}^{-1}$ were deconvoluted and curve-fitted into four pseudo-bands, namely $S_{L}, D, G_{R}$ and $G$. The $S_{L}$ band $\left(1202-1229 \mathrm{~cm}^{-1}\right.$ ) was assigned to $\mathrm{C}-\mathrm{H}$ on aromatic rings and $\mathrm{C}-\mathrm{C}$ on hydroaromatic rings mostly $\mathrm{C}_{\text {aromatic }}-\mathrm{C}_{\text {alkyl }}$ and aromatic (aliphatic) ethers. ${ }^{41}$ The $\mathrm{S}_{\mathrm{L}}$ band is considered as the measurement of cross-linking density and substitution groups. The $\mathrm{S}_{\mathrm{L}}$ band in carbon (soot), representing $\mathrm{sp}^{2}$ and $\mathrm{sp}^{3}$ structures, are the favoured sites for reaction with $\mathrm{O}_{2}$. The $\mathrm{G}$ band originates due to aromatic $\mathrm{C}=\mathrm{C}$ quadrant ring breathing of graphite structure, which refers to the polarization of atomic-plane optical modes of graphitic moieties. ${ }^{42}$ On the other hand, the $\mathrm{D}$ band is attributed to highly ordered $\mathrm{C}-\mathrm{C}$ groups between benzene rings and defects in the graphite structure. ${ }^{43}$ The shoulder band $\mathrm{G}_{\mathrm{R}}\left(1537-1540 \mathrm{~cm}^{-1}\right)$ represents amorphous carbon having 3-5 aromatic rings. ${ }^{44}$

The band area ratios such as $\mathrm{D} / \mathrm{G}$ and $\mathrm{G} / \mathrm{S}_{\mathrm{L}}$ were determined by using the spectral area count and through Raman mapping. ${ }^{\mathbf{4 1}}$ The $\mathrm{D} / \mathrm{G}$ ratio describes the concentration of aromatic rings in soot containing six or more fused benzene rings. A higher $\mathrm{D} / \mathrm{G}$ ratio indicates increased evolution of aromatic rings due to the dehydrogenation of hydroaromatic compounds. ${ }^{43}$ The increase in the aromatic rings is characteristic to carbon particles produced at higher temperatures which make them resistant to subsequent thermal devolatilization. ${ }^{\mathbf{4 0}}$

\subsection{Self-healing and self-cleaning performance of nitric acid etched PDMS composite films}

It was notable that PDMS based composite systems strongly resist acids such as $\mathrm{HCl}, \mathrm{H}_{2} \mathrm{SO}_{4}$, and $\mathrm{HNO}_{3}$. Wettability properties of the prepared PDMS/camphor soot composite films were tested qualitatively by immersing them in $1 \mathrm{M} \mathrm{HNO}_{3}$ solution for $48 \mathrm{~h}$. As shown in Fig. 6a, after $\mathrm{HNO}_{3}$ etching for $48 \mathrm{~h}$, the surface of the PDMS/camphor soot composite became hydrophilic with a water contact angle of $30^{\circ}$, indicating that the PDMS composite surface layer was distorted completely and converted to high energy surface. However, the acid etched PDMS composite regains its superhydrophobicity with a water contact angle of around $162^{\circ}$ after heating at $50{ }^{\circ} \mathrm{C}$ for about $35 \mathrm{~min}$. This etching and healing process can be repeated for six times showing that the PDMS composite surface have a strong ability to heal and regain the compromised superhydrophobicity.

It was observed that the water contact angle increases with the time lapse, which restores its superhydrophobicity after 35 min (Fig. S7 $\dagger$ ). Furthermore, the healing ability of PDMS/ camphor soot composite surface was confirmed by consecutive $\mathrm{HNO}_{3}$ treatment and heating cycles. Lowering the surface energy and recovering damaged surface of the $\mathrm{HNO}_{3}$ etched coatings under heating is possible; however, it is time consuming due to limited movement of cured PDMS composite layer. ${ }^{40}$

As shown in Fig. 6b, it was found that after heating of $\mathrm{HNO}_{3}$ etched PDMS/camphor soot composites films at $50{ }^{\circ} \mathrm{C}$ for $35 \mathrm{~min}$, the outer surface of camphor soot particles covered PDMS lowers its surface energy and regains its superhydrophobicity. 

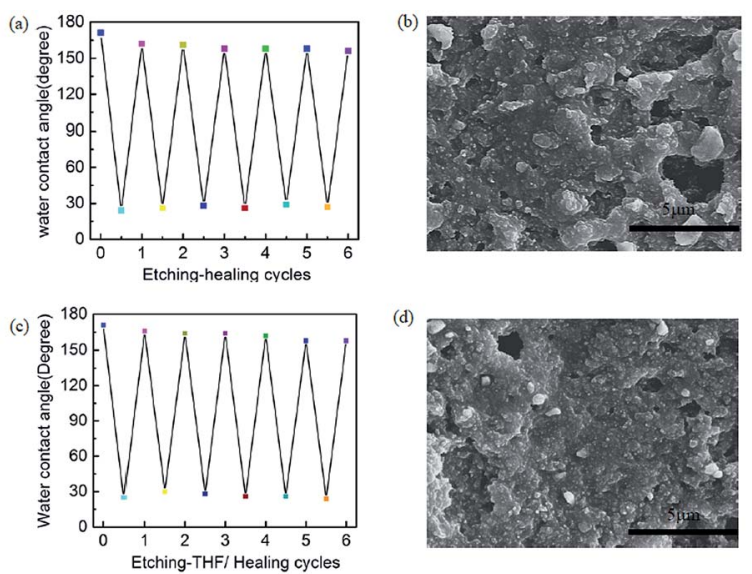

(c)

(f)
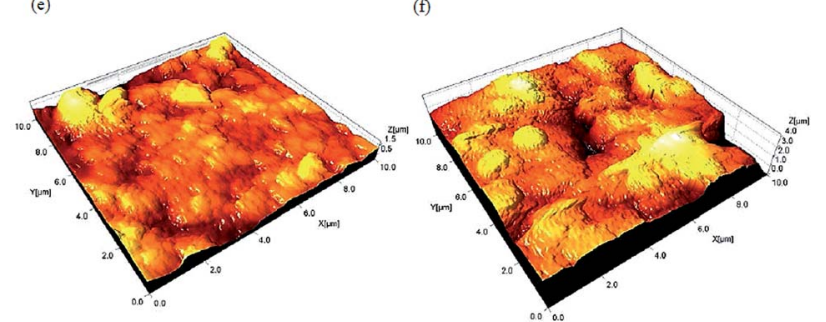

Fig. 6 (a) Water contact angle changes of PDMS/camphor soot composite films upon nitric acid etching and self-healing by heat only. (b) FESEM image of healed PDMS composite surface after heating. (c) Water contact angle changes of PDMS/camphor soot composite films upon nitric acid etching and self-healing by THF and heat. (d) FESEM image of healed PDMS composite surface after THF treatment followed by heating. (e) 3D AFM image of plain PDMS composite surface. (f) 3D AFM image of nitric acid etched PDMS composite surface.

Therefore, THF assisted healing of $\mathrm{HNO}_{3}$ etched PDMS composite layer was also investigated. As shown in Fig. 6c, after immersing in $1 \mathrm{M} \mathrm{HNO}_{3}$ solution for $48 \mathrm{~h}$, the surface of the PDMS composite reveals water contact angle of $30^{\circ}$. However, the same acid etched PDMS composites treated with THF for 5-10 s followed by heating for $5 \mathrm{~min}$ turns the coating superhydrophobic with water contact angle of around $159^{\circ}$. Therefore, THF assisted heating could be used to efficiently heal the superhydrophobic coatings. After THF treatment for 5-10 s, the camphor soot particles covered PDMS surface swells and are selfdriven towards the outer surface and healed the coatings to restore its superhydrophobicity upon heating for $5 \mathrm{~min}$. As shown in Fig. 6d, after six cycles of THF healing, the surface comprising of micro/nano-protruded particles could repair the coatings and restore its superhydrophobicity. After six cycles of THF assisted healing cycles PDMS/camphor soot composite coatings also exhibit water repellency.

As shown in Fig. S8a-d and Movie clip S3, $\dagger$ the water droplet could easily and freely roll off across the surface (tilt angle $=$ $7.3^{\circ}$ ) without leaving any sand grains, which illustrates the selfcleaning effect of the THF healed PDMS/camphor soot composite surface. Similarly, the surface morphology and roughness of the plain PDMS/camphor soot composite coated glass slides and $\mathrm{HNO}_{3}$ etched PDMS/camphor soot composite films were further examined by AFM. As illustrated in Fig. 6e, the 3D AFM images of the plain PDMS/camphor soot composite surface reveals rms roughness of $1491 \mathrm{~nm}$. It indicates the smoothness of the surface. After $\mathrm{HNO}_{3}$ etching of PDMS composite films for $48 \mathrm{~h}$, the surface roughness increases to $1921 \mathrm{~nm}$. It indicates that upon $\mathrm{HNO}_{3}$ treatment, the surface micro structure is more distorted. In Fig. 6f, it is clearly visible that after $\mathrm{HNO}_{3}$ solution treatment, surface becomes more roughened which would be the main factor that induces the change of surface wettability.

3.3.1 Self-healing ability of acid etched PDMS/camphor soot composite films. In order to elucidate the self-healing ability of the obtained $\mathrm{HNO}_{3}$ immersed PDMS/camphor soot composite surface, XPS analysis was performed to analyze the chemical compositions and the amounts of $\mathrm{C}-\mathrm{C}, \mathrm{C}-\mathrm{O}, \mathrm{Si}-\mathrm{O}$ bonding of $\mathrm{HNO}_{3}$ etched PDMS/camphor soot composite surface as shown in Fig. 7a. It can be seen that the Si 2p signal of PDMS composites did not change after the treatment while the $\mathrm{O} 1 \mathrm{~s}$ signal increased and $\mathrm{C} 1 \mathrm{~s}$ signals decreased significantly after the heating-healing process (Fig. S4b $\mathrm{b}_{\dagger}^{\dagger}$ ). The $\mathrm{HNO}_{3}$ etching of untreated camphor soot particles reveals nitrate peak at a binding energy of $405 \mathrm{eV}$ as shown in Fig. S9. $\dagger$ However, this nitrate peak is not revealed upon acid etching of PDMS/camphor soot composite films. Upon immersion in $\mathrm{HNO}_{3}$ solution for $48 \mathrm{~h}$, the generation of $-\mathrm{OH}$ groups on PDMS composite films surface causes the changes in $\mathrm{C} 1 \mathrm{~s}$ and $\mathrm{O}$ 1s signals.

Curve fitting of Si $2 \mathrm{p}_{3}, \mathrm{C}$ 1s and $\mathrm{O}$ 1s XPS spectra of PDMS composite film, $\mathrm{HNO}_{3}$ solution treated PDMS composite surface and healed by heating and THF treatment were performed by

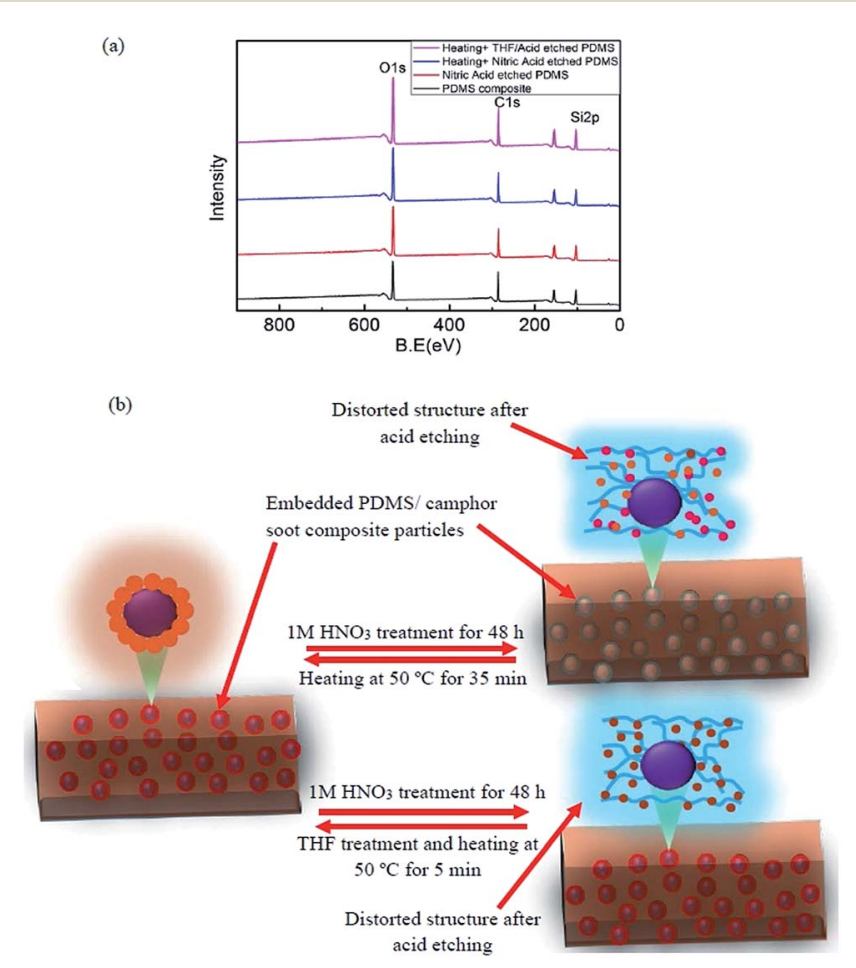

Fig. 7 (a) XPS spectra of PDMS composite surfaces, $1 M$ nitric acid treated PDMS composite surfaces, the same coating healed by only heat and healed by both THF and heat (b) schematic illustration of the self-healing process for $1 \mathrm{M}$ nitric acid treated PDMS/camphor soot composite films. 
Gaussian-Lorentzian peak shape after performing background corrections (Fig. S10a-i†). Effect of these macroscopic observations on wettability was supported by angle-resolved XPS in which the chemical composition of surfaces was demonstrated (Table S3 $\dagger$ ). As shown in Fig. S5, $\uparrow$ XPS spectra such as Si $2 \mathrm{p}_{3}, \mathrm{O}$ $1 \mathrm{~s}$, and $\mathrm{C} 1 \mathrm{~s}$ were illustrated at high-resolution to examine the major components of PDMS composites. It is clearly seen that upon $\mathrm{HNO}_{3}$ solution treatment and healing process, the peak at $102.0 \mathrm{eV}$ at the surface of PDMS composite shifts significantly to lower binding energy (101.8 eV), and the peak at $103.5 \mathrm{eV}$ shifts to lower binding energy $(103.3 \mathrm{eV})$. For $\mathrm{HNO}_{3}$ etched-healed PDMS composite surface, the $\mathrm{Si} 2 \mathrm{p}_{3}$ peak at $102.0 \mathrm{eV}$ is broad, thus being decomposed into two peaks using mixed GaussianLorentzian curve fitting. These two peaks at 101.7 and $103.3 \mathrm{eV}$ correspond to oxidized silicon.

For the surface healed by heating, at $103.3 \mathrm{eV}$ the content of Si $2 \mathrm{p}_{3}$ increases from $27.24 \%$ to $28.30 \%$ (Table $\mathrm{S} 3 \dagger$ ). However, for the surface healed by both heating and THF treatment, the content percentage of $\mathrm{Si} 2 \mathrm{p}_{3}$ decreases from 27.3 to 24.2. It indicates that the content of percentage of oxidized silicon falls upon THF treatment. Moreover, the main peak of the $\mathrm{C} 1 \mathrm{~s}$ spectrum of PDMS composite surface (Fig. S5a $\dagger$ ), $\mathrm{HNO}_{3}$ solution treated PDMS composite surface (Fig. S10a $\dagger$ ) and same surface healed by heating and THF (Fig. S10d and g, $\uparrow$ respectively) at $284.5 \mathrm{eV}$ is assigned to $\mathrm{C}-\mathrm{C}$ bond. Furthermore, other four peaks at 285.6, 286.8, 288.1 and $289.5 \mathrm{eV}$ existed with chemical shifts of $+1.1,+2.3,+3.5$ and $+4.0 \mathrm{eV}$ for each PDMS composite surfaces, which are typically assigned to $\mathrm{C}-\mathrm{O}, \mathrm{C}-\mathrm{O}-\mathrm{C}$, $\mathrm{C}=\mathrm{O}$ and $\mathrm{O}-\mathrm{C}=\mathrm{O}$ functional groups, respectively. ${ }^{35,36}$

XPS spectra of $\mathrm{O} 1 \mathrm{~s}$ peaks for surfaces such as acid etched PDMS composite surface and healed by heating only and heating by both THF/heating are demonstrated in Fig. S10. $\dagger$ The $\mathrm{O}$ 1s peak spectrum of PDMS composite surface illustrates two major peaks at 532.4 and $533.5 \mathrm{eV}$. After immersion in $\mathrm{HNO}_{3}$ solution for $48 \mathrm{~h}$, these two peaks shift to 532.1 and $533.1 \mathrm{eV}$, respectively. The $\mathrm{O}$ 1s peaks from $\mathrm{SiO}_{2}$ have a reportedly binding energy of $533.1 \mathrm{eV}$. Upon healing by heating for $35 \mathrm{~min}$, the content of $\mathrm{O} 1 \mathrm{~s}$ peaks increases from $14.43 \%$ to $21.53 \%$, which indicates more silica-like structure. ${ }^{38,39}$ However, the same surface healed by THF followed by heating for $5 \mathrm{~min}$, the content of O 1s peak decreases from $21.53 \%$ to $17.68 \%$ (Table $\mathrm{S} 3 \dagger)$. As illustrated in Fig. $7 \mathrm{~b}$, we have presented a strategy for designing self-forming and continuously self-regulating systems that are able to maintain a self-heal coating. Upon $1 \mathrm{M} \mathrm{HNO}_{3}$ treatment of PDMS/camphor soot composite film, the top composite surface layer is distorted which enhances the surface energy and damage the surface topography. However, the self-healing activity of the composite layer is triggered or accelerated upon heating at $50{ }^{\circ} \mathrm{C}$ for $35 \mathrm{~min}$. For temperature triggered surfaces, morphology of composites controls the mobile hydrogen bonding sites in the networks of PDMS/ camphor soot composites and demonstrates self-healing ability. Similarly, $\mathrm{HNO}_{3}$ treated PDMS/camphors soot composite films restored its superhydrophobicity upon THF treatment for 5-10 s followed by heating at $50{ }^{\circ} \mathrm{C}$ for $5 \mathrm{~min}$. Upon THF treatment, content of silica surface covers by hydrophobic groups $(\mathrm{C}-\mathrm{H})$ which lowers the surface energy and enhances the water contact angle. In addition, upon THF treatment, the surface of PDMS/camphor soot composite surface replaces the hydroxyl $(-\mathrm{OH})$ groups by methyl groups of PDMS/camphor soot composite surface. Specifically, upon THF treatment of the distorted composite surfaces (acid etched), rapid evaporation of the solvent triggers crosslinking of the polymer network, which swollen the surface. Because of mixing of solvent (THF) and non-solvent (water/ $\mathrm{HNO}_{3}$ ), phase separation process occurs. Furthermore, camphor soot particles are considered as mobile component that can autonomously migrated to the damaged area during rearrangement of the polymer networks upon heating at $50{ }^{\circ} \mathrm{C}$ for $5 \mathrm{~min} .{ }^{43-45}$ The driving force for particle expulsion from the composite surface is the gain in entropy of the polymer chains. It indicates that acid attacked polymer composite surface can be healed by THF treatment followed by mild heating. ${ }^{46,47}$

The Raman maps and D and G bands for acid etched PDMS/ camphor soot composite film are shown in Fig. 8. In contrast, the $\mathrm{D} / \mathrm{G}$ ratio of $\mathrm{PDMS} /$ camphor soot composite film (2.3) is higher than acid etched PDMS/camphor soot composite film (2.2), suggesting a relatively lower thermal stability of acidetched PDMS composite film. The Raman mapping was performed for $\mathrm{D}$ and $\mathrm{G}$ bands as well as $\mathrm{D} / \mathrm{G}$ band ratio. The $\mathrm{G} / \mathrm{S}_{\mathrm{L}}$ ratio is the fraction of $\mathrm{C}=\mathrm{C}$ graphitic structures to $\mathrm{C}_{\text {aromatic }}{ }^{-}$ $\mathrm{C}_{\text {alkyl }}$ aromatic structures. ${ }^{41} \mathrm{~A}$ higher $\mathrm{G} / \mathrm{S}_{\mathrm{L}}$ ratio indicates the loss of aromatic carbon structures with the progressive removal of oxygen-containing functional groups. A greater $\mathrm{G} / \mathrm{S}_{\mathrm{L}}$ ratio also suggests a stronger contribution of graphitic moieties with higher environmental stability upon $\mathrm{HNO}_{3}$ treatment of PDMS/ camphor soot composite surface. ${ }^{48}$ The $\mathrm{G} / \mathrm{S}_{\mathrm{L}}$ ratio of acid etched composite surface (6.0) is higher than untreated PDMS composite film (2.9) demonstrating a relatively lower oxygen content with high thermal and structural stability.

\subsection{Mechanical test using the atomic force microscope}

It is essential to measure the mechanical properties of such coated surfaces, particularly when they get exposed to external harsh environment. Therefore, using AFM, we have investigated the mechanical properties at the level of nanoscale. Graphical representation for the calculation of mechanical properties such as stiffness ' $\delta$ ', work of plastic deformation ' $W_{\text {plastic' }}$ ' and effective work of adhesion ' $W$ adhesive' extracted from typical force-displacement curves are illustrated in Fig. 9. The AFM tip was considered as the probe used to perform the force measurements. ${ }^{49-53}$ As an example, Fig. 10 shows obtained force-displacement curves of four different samples recorded by using AFM tip. The plastic work $W_{\text {plastic }}$ and the effective adhesive work $W_{\text {adhesive }}$ are given by the integrals of the $y$ axis (force) with the $x$-axis (distance) on approach and retract, respectively (highlighted areas in Fig. 9). In addition, depth of indentation of four different samples is also comparatively illustrated in Fig. 10 and 11.

As illustrated in Fig. 10a, plain PDMS/camphor soot composite surface was indented by almost $600 \mathrm{~nm}$ with a maximum indentation load of $300 \mathrm{nN}$. However, PDMS/ camphor soot composite surface healed by temperature via 

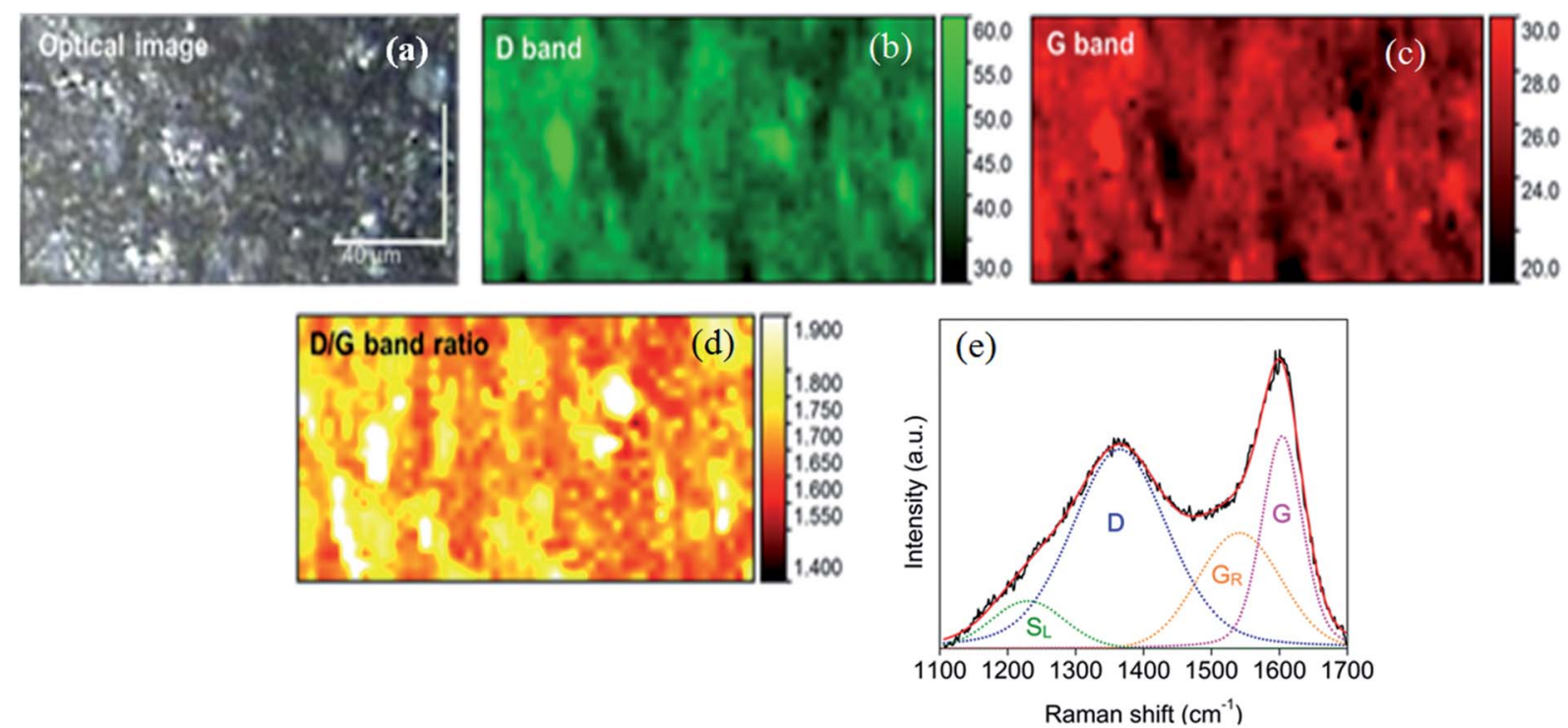

Fig. 8 Chemical maps generated through Raman spectroscopy of healed nitric acid treated PDMS/camphor soot composite film upon THF treatment heating. (a) Optical CCD image, (b) D band (mapping region: $1350-1365 \mathrm{~cm}^{-1}$ ). (c) G band (mapping region: $1537-1540 \mathrm{~cm}{ }^{-1}$ ). (d) $D / G$ band ratio. (e) Raman spectral acquisition at $514 \mathrm{~nm}$ (from 1100 to $1700 \mathrm{~cm}^{-1}$ ).

oxygen plasma treatment shows $500 \mathrm{~nm}$ depth of indentation. Accordingly, the slope of the upper portion of the unloading curve during the initial stages of unloading illustrates the stiffness of the material. It is observed that plain PDMS composite surface was much steeper than healed PDMS/ camphor soot composite surface. Thus it is confirmed that healed PDMS composite surface (obtained PDMS composite surface after 12 no's of etching-healing cycles) is more mechanically stronger than plain PDMS composite sample. It has long been known that to amend the surface properties of PDMS composites, different techniques can be employed that involve physical or chemical treatments. Particularly $\mathrm{O}_{2}$ plasma etching has been widely used to modify the surfaces of PDMS. However, the characteristics of $\mathrm{O}_{2}$-plasma-modified PDMS surfaces progressively change during aging, and the surface recovers its hydrophobicity. Particularly, during the heating-

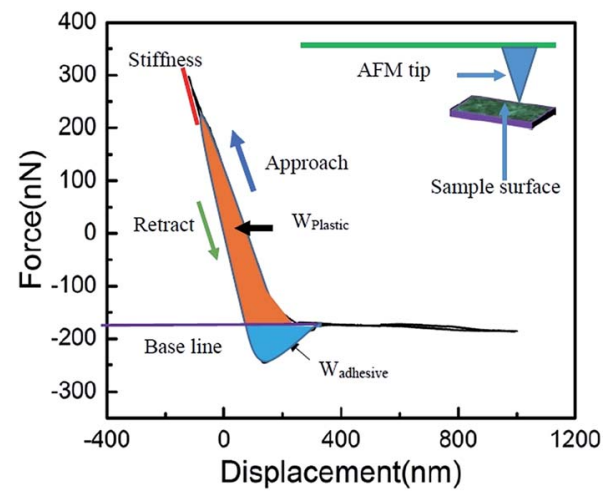

Fig. 9 Graphical representation of mechanical properties such as stiffness ' $\delta$ ', plastic deformation work ' $W$ plastic' and effective adhesion work ' $W$ adhesive', which can be extracted from a typical forcedisplacement curve. etching process, the top portion of PDMS composites gets significantly oxidized. ${ }^{54}$ In addition, during heating-healing cycles, the PDMS composite generates more roughened surface and agglomeration of silica particles, which enhances the mechanical strength of composites. Similarly, $W_{\text {plastic }}$ and $W_{\text {adhesive }}$ also play important role in the force measurements curves of PDMS composites. An increase in the $W_{\text {plastic }}(250 \mathrm{fJ})$ of the healed PDMS composite surface is observed for the formation of silica network. It results in more plastic deformation of the sample. For materials with a low $W_{\text {plastic }}$ can result in significant decrease in the composite's elasticity. Furthermore,
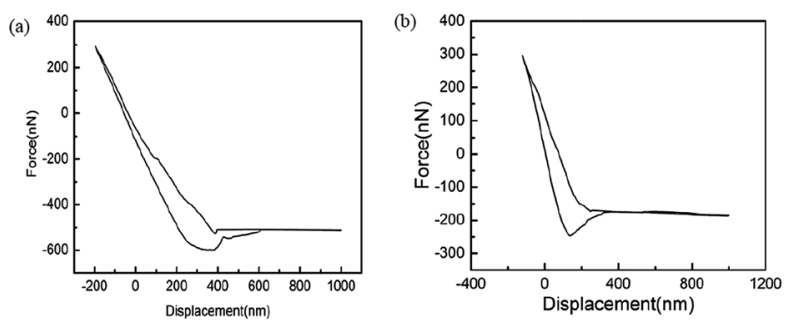

(c)

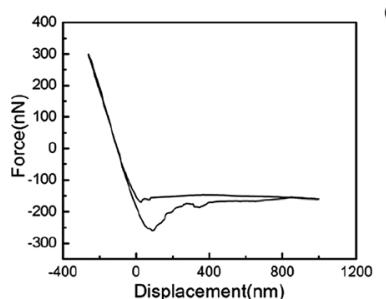

(d)

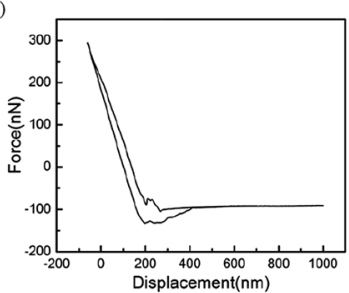

Fig. 10 Force-displacement curve for (a) PDMS composite surface, (b) healed PDMS/camphor soot coated surface after 12 no's cycles of etching-heating process, (c) healed PDMS composite surface after heating only, and (d) healed PDMS composite surface after THF treatment followed by heating. 

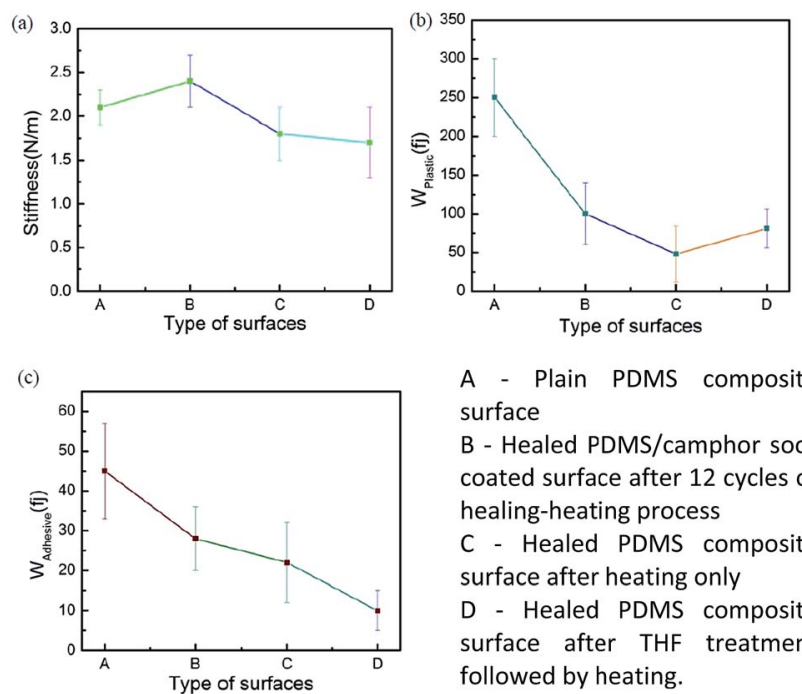

\begin{abstract}
A - Plain PDMS composite surface

B - Healed PDMS/camphor soot coated surface after 12 cycles of healing-heating process

C - Healed PDMS composite surface after heating only

D - Healed PDMS composite surface after THF treatment followed by heating.
\end{abstract}

Fig. 11 Mechanical properties of PDMS composite surface: (a) stiffness, (b) plastic deformation work $W_{\text {plastic, }}$ and (c) adhesion work $W_{\text {adhesive }}$ of the material.

work of adhesion ( $\left.W_{\text {adhesive }}\right)$ is an essential factor, which signifies the adhesion between the tip and composite surface during retraction stage. A decrease in work of adhesion of $15 \mathrm{fJ}$ for PDMS composite surface signifies that less amount of work is required to break the contacts between the AFM tip and composite surface. During retraction, surface forces are predominantly van der Waals. Consequently, the results from the individual force-displacement curves showed a broader span of $W_{\text {plastic }}$ and $W_{\text {adhesive }}$ leading to increased error bar as shown in Fig. 11.

Similarly, to test mechanical properties of $1 \mathrm{M} \mathrm{HNO}_{3}$ etched PDMS composite samples; we have illustrated force measurements in Fig. 10c and d. As shown in Fig. 10c, PDMS/camphor soot composite surface healed by heating was indented by only $360 \mathrm{~nm}$ with a maximum indentation load of $300 \mathrm{nN}$. Furthermore, maximum depth of indentation was $300 \mathrm{~nm}$ for PDMS composite surface healed by both THF and heating. After immersion of PDMS composites in $1 \mathrm{M}$ nitric acid solution for $48 \mathrm{~h}$, surface undergoes degradation and cracking due to chemical attack. Furthermore, $\mathrm{HNO}_{3}$ degrades the amorphous components and leaving the crystals intact. Upon heating at $50{ }^{\circ} \mathrm{C}$ for $30 \mathrm{~min}$, the damaged surface undergoes rearrangement, which results in the enhancement of superhydrophobicity. It is clearly observed that depth of indentation for healed sample for $\mathrm{HNO}_{3}$ etched sample and plain PDMS composite is nearly equal. It was also observed that plain PDMS composite surface was much steeper than PDMS/camphor soot composite surface healed by temperature and both THF/temperature treatment. Hence, it is confirmed that healed PDMS composite surface (both obtained PDMS composite surface healed by heating only and THF/heating) are more mechanically stronger than plain PDMS composite sample. ${ }^{55,56}$ During heating-healing cycles, the PDMS composites generate the long chain of silica molecules, which results in the enhancement of hardness. A decrease in the $W_{\text {plastic }}$ of $48 \mathrm{fJ}$ for the healed PDMS composite surface by heating only significantly demonstrates low hardness of the sample. As a result, low hardness generates more elasticity of the sample. In contrast, PDMS composite surface healed by both THF/heating shows enhanced $W_{\text {plastic. }}$ Upon THF treatments of $\mathrm{HNO}_{3}$ etched PDMS composites, surface swells and further enhance the diffusion pathways and thus allowing the THF to more freely permeate through the PDMS matrix to etch away the oxide particles embedded in the matrix. Further, upon heating for 5$10 \mathrm{~s}$, surface enhances the smoothness. In addition, work of adhesion (8 fJ) for PDMS composite surface healed by heating and $\mathrm{THF} /$ heating is significantly reduced compared to plain PDMS composite samples. Hence, for particular industrial application, samples can be adjusted for optimum repellency (water) or mechanical stability.

\section{Conclusions}

In summary, by combining the spraying technique and solution immersion process, we have fabricated a durable and self-healing superhydrophobic PDMS/camphor soot composite coating on a glass slide and stainless steel substrates. The resultant coating shows a robust resistance upon several sand abrasion tests and reveals excellent superhydrophobicity with a low sliding angle. The PDMS/camphor soot composite surface is comprised of the combinations of micro/nano-structures and low surface energy chemical compositions. The $\mathrm{O}_{2}$ plasma treatment adversely affected the surface chemistry and structures although the same were restored along with its superhydrophobicity through a simple heating process. The self-healing ability of PDMS/camphor soot composite surface is caused by the reorganization of surface structure and generation of low surface energy molecules. The surface modification of PDMS/camphor soot composite surface was achieved by the treatment of $1 \mathrm{M}$ $\mathrm{HNO}_{3}$ solution. The surface layer of the composite was immediately oxidized and turned hydrophilic. The same surface healed and illustrates superhydrophobicity upon simple heating for $35 \mathrm{~min}$. However, it is observed that the same $\mathrm{HNO}_{3}$ etched PDMS/camphor soot composite surface healed upon THF treatment followed by heating for $5 \mathrm{~min}$. In addition, we have investigated the mechanical force measurements between the AFM tip and PDMS composite surface. We have also measured mechanical properties such as stiffness, plastic work of indentation, effective work of adhesion and depth of indentation self-healing PDMS composites. We have shown that the depth of indentation for PDMS composite surface is more than healed PDMS composite surfaces. Similarly, optimum mechanical stability at the cost of slightly reduced repellency against water is achieved by exposure of samples to oxygen plasma etching and $1 \mathrm{M} \mathrm{HNO}_{3}$ etching process. Finally, the results clearly suggest that the micromechanical properties of self-healed PDMS composites modified by the $\mathrm{O}_{2}$ plasma etching and acid etching are reduced compared to plain PDMS composites. For a better understanding of such an effect, investigations about the plasticity and elasticity of etched surfaces could be undertaken as future study. We believe that this novel method for developing self-healing PDMS/ camphor soot composite surface can be used for several important applications. 


\section{Acknowledgements}

The authors would like to thank Dr Siva Kumar Gunda, postdoctoral fellow in Micro \& Nano-scale Transport Laboratory at York University for his assistance with the experimental set-up. The financial support to SM as Kaneff Professorship is acknowledged here. The authors would also like to thank Dr Rana N. Sodhi (University of Toronto) and Dr Jason Maley (Saskatchewan Structural Sciences Centre at University of Saskatchewan) for their respective assistances in XPS characterization as well as Raman spectroscopy and AFM imaging.

\section{Notes and references}

1 (a) X. Zhang, F. Shi, J. Niu, Y. Jiang and Z. Wang, J. Mater. Chem., 2008, 18, 621; (b) M. Spaetha and W. Barthlott, Adv. Sci. Technol., 2008, 60, 38; (c) P. R. Waghmare, N. S. K. Gunda and S. K. Mitra, Sci. Rep., 2014, 4, 7454.

2 T. Onda, S. Shibuichi, N. Satoh and K. Tsujii, Langmuir, 1996, $12,2125$.

3 B. Bhushan, Y. C. Jung and K. Koch, Langmuir, 2009, 25, 3240.

4 X. M. Li, D. Reinhoudt and M. Crego-Calama, Chem. Soc. Rev., 2007, 36, 1350.

5 S. Farhadi, M. Farzaneh and S. A. Kulinich, Appl. Surf. Sci., 2011, 257, 6264.

6 (a) Y. Li, S. Chen, M. Wu and J. Sun, Adv. Mater., 2014, 26, 3344; (b) T. Dikíc, W. Ming, R. A. T. M. van Benthem, A. C. C. Esteves and G. de With, Adv. Mater., 2012, 24, 3701; (c) C. H. Xue and J. Z. Ma, J. Mater. Chem., 2013, 1, 4146; (d) J. Borges, L. C. Rodrigues, R. L. Reis and F. João, Adv. Funct. Mater., 2014, 24, 5624.

7 (a) M. D. Hager, P. Greil, C. Leyens, S. Zwaag and U. S. Schubert, Adv. Mater., 2010, 22, 5424; (b) Y. Lai, J. Huang, Z. Cui, M. Ge, K.-Q. Zhang, Z. Chen and L. Chi, Small, 2016, 12, 2203.

8 Y. Chen, A. M. Kushner, G. A. Williams and Z. Guan, Nat. Chem., 2012, 4, 467.

9 (a) L. Huang, N. Yi, Y. Wu, Y. Zhang, Q. Zhang, Y. Huang, Y. Ma and Y. Chen, Adv. Mater., 2013, 25, 2224; (b) Y. Liu, Z. Liu, Y. Liu, H. Hu, Y. Li, P. Yan, B. Yu and F. Zhou, Small, 2015, 11, 426; (c) Y. Zhao, J. Fickert, K. Landfester and D. Crespy, Small, 2012, 8, 2954; (d) H. Wang, H. Zhou, A. Gestos, J. Fang, H. Niu, J. Ding and T. Lin, Soft Matter, 2013, 9, 277.

10 N. Puretskiy, G. Stoychev, A. Synytska and L. Loniov, Langmuir, 2012, 28, 3679.

11 N. Puretskiy, G. Stoychev, M. Stamm and L. Lonov, ACS Appl. Mater. Interfaces, 2010, 2, 2944.

12 Y. Li, L. Li and J. Sun, Angew. Chem., Int. Ed., 2010, 49, 6129.

13 Y. Li, L. Li and J. Q. Sun, Angew. Chem., Int. Ed., 2010, 49, 6265.

14 D. D. Chenn, Y. Ma and J. Q. Sun, Acta Polym. Sin., 2012, 10, 1047.

15 S. Pan, A. K. Kota, J. M. Mabry and A. Tuteja, J. Am. Chem. Soc., 2013, 135, 578.
16 A. Tropmann, L. Tanguy, P. Koltay, R. Zengerle and L. Riegger, Langmuir, 2012, 28, 8292.

17 X. Zhang, H. Ye, B. Xiao, L. Yan, H. Lv and B. Jiang, J. Phys. Chem. C, 2010, 114, 19979.

18 X. Liu, Y. Xu, Z. Chen, K. Ben and Z. Guan, RSC Adv., 2015, 5, 1315.

19 (a) X. Deng, L. Mammen, H. Butt and D. Vollmer, Science, 2012, 335, 67; (b) X. Liu, Y. Xu, K. Ben, Z. Chen, Y. Wang and Z. Guan, Appl. Surf. Sci., 2015, 339, 94; (c) X. Liu, Y. Xu, Z. Chen, K. Ben and Z. Guan, RSC Adv., 2015, 5, 1315; (d) L. Yuan, F. Zhang, W. P. Liu, X. Y. Gu, W. Zhang, D. Y. Huo, X. Y. Zhang, Y. Y. Wang and C. S. Peng, Adv. Mater. Res., 2013, 815, 610.

20 R. P. S. Chakradhar, V. D. Kumar, J. L. Rao and B. J. Basu, Appl. Surf. Sci., 2011, 257, 8569.

21 C. Kapridaki and P. Maravelaki-Kalaitzaki, Prog. Org. Coat., 2013, 76, 400.

22 (a) B. N. Sahoo and K. Balasubramanian, RSC Adv., 2014, 4, 11331; (b) B. N. Sahoo and K. Balasubramanian, RSC Adv., 2015, 5, 6743; (c) B. N. Sahoo, K. Balasubramanian and M. M. Sucheendran, J. Phys. Chem. C, 2015, 119, 14201; (d) B. N. Sahoo and K. Balasubramanian, J. Colloid Interface Sci., 2014, 436, 111.

23 T. Shih, J. Ho, C. Chen, W. Whang and C. Chen, Appl. Surf. Sci., 2007, 253, 9381.

24 A. Sadezky, H. Muckenhuber, H. Grothe, R. Niessner and U. Poschl, Carbon, 2005, 43, 1731.

25 D. N. Shooto and E. D. Dikio, Int. J. Electrochem. Sci., 2011, 6, 1269.

26 Z. Y. Deng, W. Wang, L. Mao, C. F. Wang and S. Chen, J. Mater. Chem. A, 2014, 2, 4178.

27 (a) X. Deng, L. Mammen, Y. Zhao, P. Lellig, K. Mullen, C. Li, H.-J. Butt and D. Vollmer, Adv. Mater., 2011, 23, 2962; (b) S. Hoshian, V. Jokinen and S. Franssila, Soft Matter, 2016, 12, 6526.

28 C.-Y. Yang, S.-I. Chuang, Y.-H. Lo, H.-M. Cheng, J.-G. Duh and P.-Y. Chen, J. Mater. Chem. A, 2016, 4, 3406.

29 H. Wang, Y. Xue, J. Ding, L. Feng, X. Wang and T. Lin, Angew. Chem., Int. Ed., 2011, 50, 11433.

30 C.-H. Xue, Z.-D. Zhang, J. Zhang and S.-T. Jiaa, J. Mater. Chem. A, 2014, 2, 15001.

31 M. Wu, B. Ma, T. Pan, S. Chen and J. Sun, Adv. Funct. Mater., 2016, 26, 569.

32 (a) Y. Li, S. Chen, M. Wu and J. Sun, Adv. Mater., 2014, 26, 3344; (b) T. Lv, Z. Cheng, E. Zhang, H. Kang, Y. Liu and L. Jiang, Small, 2017, 13, 1503402.

33 J. N. Lee, C. Park and G. M. Whitesides, Anal. Chem., 2003, 75, 6544 .

34 D. Briggs and G. Beamson, Anal. Chem., 1993, 65, 1517.

35 J.-W. He, X. Xu, J. S. Corneille and D. W. Goodman, Surf. Sci., 1992, 279, 119.

36 D. Yang, A. Velamakanni, G. Bozoklu, S. Park, M. Stoller, R. D. Piner, S. Stankovich, I. Jung, D. A. Field, C. A. Ventrice and R. S. Ruoff, Carbon, 2009, 47, 145.

37 (a) T.-C. Chiang and F. Seitz, Ann. Phys., 2001, 10, 61; (b) S. Yumitori, J. Mater. Sci., 2000, 35, 139; (c) C. Kozlowski and P. M. A. Sherwood, J. Chem. Soc., Faraday Trans. 1, 
1984, 80, 2099; (d) M. I. Awad, M. M. Saleh and T. Ohsaka, J. Solid State Electrochem., 2008, 12, 251; (e) G. Zhang, S. Sun, D. Yang, J.-P. Dodelet and E. Sacher, Carbon, 2008, 46, 196; (f) D. Boukhvalov and M. Katsnelson, Phys. Rev. B: Condens. Matter Mater. Phys., 2008, 78, 1.

38 Y.-L. Huang, H.-W. Tien, C.-C. M. Ma, S.-Y. Yang, S.-Y. Wu, H.-Y. Liu and Y.-W. Ma, J. Mater. Chem., 2011, 21, 18236.

39 (a) T. Szabo, O. Berkesi, P. Forgo, K. J. Povits, Y. Sanakis, D. Petridis and I. Dekany, Chem. Mater., 2006, 18, 2740; (b) W. W. Cai, R. D. Piner, F. J. Stadermann, S. Park, M. A. Shaibat, Y. Ishii, D. X. Yang, A. Velamakanni, S. J. An, M. Stoller, J. H. An, D. M. Chen and R. S. Ruoff, Science, 2008, 321, 1815; (c) A. Lerf, H. Y. He, M. Forster and J. Klinowski, J. Phys. Chem. B, 1998, 102, 4477; (d) H. Y. He, J. Klinowski, M. Forster and A. Lerf, Chem. Phys. Lett., 1998, 287, 53; (e) L. A. Langley and D. H. Fairbrother, Carbon, 2007, 45, 47; (f) J. Li, L. Vaisman, G. Marom and J. K. Kim, Carbon, 2007, 45, 744.

40 P. Kim, A. Johnson, C. W. Edmunds, M. Radosevich, F. Vogt, T. G. Rials and N. Labbe, Energy Fuels, 2011, 25, 4693.

41 S. Nanda, R. Azargohar, J. A. Kozinski and A. K. Dalai, BioEnergy Res., 2014, 7, 174.

42 S. Reich and C. Thomsen, Philos. Trans. R. Soc., A, 2004, 362, 2271.

43 X. j. Li, j. Hayashi and C. Z. Li, Fuel, 2004, 85, 1700.
44 X. Yang, H. Yu, L. Wang, R. Tong, M. Akram, Y. Chen and X. Zhai, Soft Matter, 2015, 11, 1242.

45 C.-Y. Hui and R. Long, Soft Matter, 2012, 8, 8209.

46 K.-S. Koh, J. Chin, J. Chia and C.-L. Chiang, Micromachines, 2012, 3, 427.

47 M. L. Chabinye, D. T. Chiu, J. C. Mcdonald, A. D. Strook, J. F. Christian, A. F. Karger and G. M. Whitesides, Anal. Chem., 2001, 73, 4491.

48 D. M. Keown, X. Li, J. I. Hayashi and C. Z. Li, Fuel Process. Technol., 2008, 89, 1429.

49 I. M. Pelin, A. Piednoir, D. Machon, P. Farge, C. Pirat and S. M. M. Ramos, J. Colloid Interface Sci., 2012, 376, 262.

50 M. Griepentrog, G. Krämer and B. Cappella, Polym. Test., 2013, 32, 455.

51 C. Browne, R. F. Tabor, F. Grieser and R. R. Dagastine, J. Colloid Interface Sci., 2015, 449, 236.

52 M. Chyasnavichyus, S. L. Young, R. Geryak and V. V. Tsukruk, Polymer, 2016, 102, 317.

53 O. U. Vakarelski, E. Q. Li and S. T. Thoroddsen, Colloids Surf., A, 2014, 462, 259.

54 J. Wang, J. Li, L. Xie, C. Shi, Q. Liu and H. Zeng, Chem. Eng. J., 2016, 303, 646.

55 D. Bodas and C. Khan-Malek, Sens. Actuators, B, 2007, 123, 368.

56 R. A. Lawton, C. R. Price, A. F. Runge, W. J. Doherty and S. S. Saavedra, Colloids Surf., A, 2005, 253, 213. 